\title{
The human papillomavirus oncoproteins: a review of the host pathways targeted on the road to transformation
}

\author{
James A. Scarth ${ }^{1,2, *}$, Molly R. Patterson ${ }^{1,2}$, Ethan L. Morgan ${ }^{1,2} \dagger$ and Andrew Macdonald $1,2, *$
}

\begin{abstract}
Persistent infection with high-risk human papillomaviruses (HR-HPVs) is the causal factor in over $99 \%$ of cervical cancer cases, and a significant proportion of oropharyngeal and anogenital cancers. The key drivers of HPV-mediated transformation are the oncoproteins E5, E6 and E7. Together, they act to prolong cell-cycle progression, delay differentiation and inhibit apoptosis in the host keratinocyte cell in order to generate an environment permissive for viral replication. The oncoproteins also have key roles in mediating evasion of the host immune response, enabling infection to persist. Moreover, prolonged infection within the cellular environment established by the HR-HPV oncoproteins can lead to the acquisition of host genetic mutations, eventually culminating in transformation to malignancy. In this review, we outline the many ways in which the HR-HPV oncoproteins manipulate the host cellular environment, focusing on how these activities can contribute to carcinogenesis.
\end{abstract}

\section{INTRODUCTION}

Papillomaviruses are small non-enveloped icosahedral viruses, possessing a circular double-stranded DNA (dsDNA) genome of approximately $8 \mathrm{~kb}$ in length [1]. To date, over 400 isolates from a wide variety of fish, reptiles, birds and mammals have been reported in the Papillomaviridae family, over 200 of which infect humans [2,3].

Received 17 September 2020; Accepted 25 November 2020; Published 11 January 2021

Author affiliations: 'School of Molecular and Cellular Biology, Faculty of Biological Sciences, University of Leeds, Leeds, West Yorkshire, LS2 $9 \mathrm{JT}$, UK; ${ }^{2}$ Astbury Centre for Structural Molecular Biology, University of Leeds, Leeds, West Yorkshire, LS2 9JT, UK.

*Correspondence: James A. Scarth, bsjasc@leeds.ac.uk; Andrew Macdonald, a.macdonald@leeds.ac.uk

Keywords: cancer; HPV; keratinocyte; oncoprotein; signalling.

Abbreviations: anti-PD-L1, anti-programmed death-ligand 1; ATM, ataxia-telangiectasia mutated; ATR, ataxia-telangiectasia and Rad3-related; BAK, Bcl-2 homologous antagonist/killer; BPV, bovine papillomavirus; CARM1, coactivator associated arginine methyltransferase 1; CBP, CREB-binding protein; CCEPR, cervical carcinoma expressed PCNA regulatory; circRNA, circular RNA; CR, conserved region; DANCR, differentiation antagonizing non-protein coding RNA; DAPK1, death associated protein kinase 1; DDR, DNA damage response; DISC, death-induced signalling complex; DLG1, discs large homologue 1; DREAM, dimerization partner, pRb-like, E2F and multi-vulval class B; dsDNA, double-stranded DNA; DVL2, dishevelled 2; E, early; E6-AP, E6-associated protein; EGFR, epidermal growth factor receptor; E5KO, E5 knock out; EMT, epithelial-mesenchymal transition; ERK1/2, extracellular signal-regulated kinase 1/2; FADD, Fas-associated protein with death domain; FAM83H-AS1, FAM83H antisense RNA 1; FOXM1, forkhead box protein M1; GLUT1, glucose transporter 1; GSK3 $\beta$, glycogen synthase kinase 3 beta; HAT, histone acetyltransferase; HDAC, histone deacetylase; HNSCC, head and neck squamous cell carcinoma; HOTAIR, HOX transcript antisense intergenic RNA; HPV+, HPV-positive; HPV, human papillomavirus; HR-HPV, high-risk human papillomavirus; HSPG, heparin sulphate proteoglycan; hTERT, human telomerase reverse transcriptase; IFN, interferon; IGF1R, insulin-like growth factor receptor; IL-6, interleukin-6; IL-18BP, interleukin-18 binding protein; INSR, insulin receptor; IRF, IFN regulatory factor; ISG, interferon-stimulated gene; JAK, Janus kinase; JNK1/2, c-Jun N-terminal kinase 1/2; K14, keratin-14; L, late; IncRNA, long non-coding RNA; MALAT1, metastasis associated lung adenocarcinoma transcript 1; MAML1, mastermind-like protein 1; MAPK, mitogen-activated protein kinase; MDM2, mouse double minute 2 homologue; MHC, major histocompatibility complex; miRNA, micro RNA; mTORC1, mammalian target of rapamycin complex 1; MZF1, myeloid zinc finger 1; ncRNA, non-coding RNA; NES, nuclear export signal; $\mathrm{NHERF}, \mathrm{Na}^{+} / \mathrm{H}^{+}$exchange regulatory factor 1; NICD, Notch intracellular domain; NKX2-1, NK2 homeobox 1; NLS, nuclear localization signal; ori, origin of DNA replication; PAE, early polyadenylation site; PAL, late polyadenylation site; PBM, PDZ-binding motif; PcG, polycomb group; PDGFR, platelet-derived growth factor receptor; PDZ, PSD-95/DLG/ZO-1; PI3K, phosphatidylinositol 3-kinase; PIP2, phosphatidylinositol 4,5-bisphosphate; PIP3, phosphatidylinositol 3,4,5-trisphosphate; PKC, protein kinase C; pRb, retinoblastoma protein; PRC2, Polycomb repressive complex 2; PRMT1, protein arginine methyltransferase 1; PRR, pattern recognition receptor; PTEN, phosphatase and tensin homologue; ROS, reactive oxygen species; RTK, receptor tyrosine kinase; SIAH1, seven in absentia homologue 1; SNX27, sorting nexin 27; Sp1, specificity protein 1; STAT, signal transducer and activator of transcription; STK4, serine/threonine-protein kinase 4; SV40, simian virus 40; TAZ, transcriptional coactivator with PDZ-binding motif; TEAD, TEA domain; TGN, trans-Golgi network; TINCR, tissue differentiation-inducing non-protein coding RNA; TLR9, Toll-like receptor 9; TMD, transmembrane domain; TMPOP2, thymopoietin pseudogene 2; TNFR1, tumour necrosis factor receptor 1; TRAIL, TNF-related apoptosis-inducing ligand; TSC1/2, tuberous sclerosis complexes 1/2; TYK2, non-receptor tyrosine kinase 2; URR, upstream regulatory region; USF1, upstream stimulating factor 1; USF2, upstream stimulating factor 2; UV, ultraviolet; v-ATPase, vacuolar $\mathrm{H}^{+}$-ATPase; YAP1, yes-associated protein 1.

†Present address: Tumour Biology Section, Head and Neck Surgery Branch, National Institute on Deafness and Other Communication Disorders, National Institute of Health, Bethesda, MD 20892, USA.

$001540 \odot 2021$ The Authors 
The study of human papillomaviruses (HPVs) has largely been driven by the severity of HPV-associated pathologies: whilst the HPVs that infect the cutaneous epithelium and typically result in benign wart or verruca formation, as well as the low-risk mucosal HPV types 6 and 11 associated with genital warts, have received some attention, the greatest focus has been on the high-risk HPVs (HR-HPVs) associated with the development of cancer $[1,4]$. This link between HPV infection and cancer was first established over 35 years ago when HPV16 DNA was found to be present in a large proportion of cervical cancer biopsies [5]. However, it is important to consider that the majority of HR-HPV infections will not progress to cancer; indeed $85 \%$ of cases are subclinical transient infections [6]. There are currently 15 recognized HR-HPV types: HPV16, 18, 31, 33, 35, 39, $45,51,52,56,58,59,68,73,82$ [7]. Together, HR-HPVs are responsible for $>99.7 \%$ of cervical cancer cases, of which $55 \%$ are HPV 16-positive and $15 \%$ are HPV18-positive, along with a growing number or oropharyngeal cancers [8]. Cancer of the cervix is the fourth most common malignancy in women worldwide and the fourth leading cause of cancerrelated deaths in women: in 2018, around 570000 people were diagnosed with cervical cancer and over 300000 deaths worldwide could be attributed to the disease [9]. Furthermore, HR-HPV infection is associated with cancers at a variety of other anogenital sites: around $50 \%$ of penile, $25 \%$ of vulvar, $80 \%$ of vaginal and close to $90 \%$ of anal cancers are HPV-driven [10].

Although their expression is insufficient for progression to cancer, the main drivers of HPV-associated pathologies are the oncoproteins E5, E6 and E7 [11]. Together, they act to prolong the proliferation, and delay differentiation, of host keratinocytes to provide an environment suitable for viral replication. Many of the mechanisms by which this is achieved have been widely studied: HR-HPV E7 drives S-phase re-entry via binding to and inducing degradation of the retinoblastoma protein $(\mathrm{pRb})$ and the related pocket proteins $\mathrm{p} 107$ and $\mathrm{p} 130$ [12-16], whilst E6 concurrently targets p53 for proteasomemediated degradation, inhibiting pro-apoptotic signalling in response to DNA damage caused by the abnormal S-phase entry $[17,18]$. Additionally, E6 modulates a multitude of host signalling pathways, including the Hippo and JAK/ STAT pathways, to further promote proliferation and delay differentiation [19-21]. Whilst the role of HPV E5 is not well understood, it has been shown to drive cell proliferation by promoting epidermal growth factor receptor (EGFR)-induced signalling [22-24]. Importantly, if the expression of the viral oncoproteins becomes dysregulated, such as in the context of a persistent infection, cancer progression becomes more likely [11].

In this review, as well as outlining the basic biology of HPV and its life cycle, we aim to provide a comprehensive overview of the biological activities of each HPV oncoprotein in turn, with a particular focus on those of the HR-HPVs. We will illustrate the vital contributions each oncoprotein makes to the virus life cycle as well as addressing how these various functions may contribute towards carcinogenesis.

\section{HUMAN PAPILLOMAVIRUSES HPV genome organization}

The HPV genome is organized into three functional sections: the early (E) region, the late (L) region, and an upstream regulatory region (URR) (Fig. 1a) [8]. Together, the early and late regions consist of nine ORFs, six in the early region (E1, E2, $\mathrm{E} 1 \wedge \mathrm{E} 4, \mathrm{E} 5, \mathrm{E} 6, \mathrm{E} 7$ and $\mathrm{E} 8)$ and two in the late region (L1 and L2), whilst the URR contains the origin of DNA replication (ori) as well as the transcription-factor binding sites required for the regulation of RNA-polymerase-II-dependent transcription. The three regions are separated by early and late polyadenylation sites (PAE and PAL, respectively). The HPV genome contains two major promoters: p97 in HPV16 and 31 (p105 in HPV18) is responsible for expression of the early genes and lies upstream of the E6 ORF, and p670 in HPV 16 (p811 in HPV18 and p742 in HPV31) is responsible for differentiation-dependent late gene expression and lies within the E7 ORF [25-27]. Although there are multiple minor promoters, their functions are poorly characterized [27]. Importantly, the HR-HPV E6 and E7 oncoproteins are encoded by a single bicistronic mRNA transcript with splicing allowing for the expression of each ORF [27].

\section{HPV life cycle}

The life cycle of HPV is intrinsically linked to the epithelial differentiation programme. For an infection to be established, virions must gain access to the basal lamina of the stratified epithelium via microlesions or by entering cells at the squamo-columnar junction [1,28]. Primary attachment of virions involves binding of the L1 capsid protein to heparin sulphate proteoglycans (HSPGs) on the basement membrane or on the surface of basal keratinocytes [29]. This induces conformational changes in the capsid structure, resulting in the exposure of the minor capsid protein L2 and binding to secondary receptors, the identity of which remains controversial (see [30] for a review). This is followed by endocytosis, which occurs via a clathrin-, caveolin-, cholesterol-, lipid raft- and dynamin-independent mechanism similar to micropinocytosis [31].

Capsid disassembly occurs in the late endosome, followed by trafficking of the viral genome, in complex with L1 and L2, towards the trans-Golgi network (TGN) [32-34]. This is mediated by direct interactions between $\mathrm{L} 2$ and components of the retrograde transport machinery such as the retromer complex, an ability conferred by the C-terminal cellpenetrating peptide possessed by L2 [35-37]. Onward nuclear trafficking is critically dependent upon the breakdown of the nuclear envelope during mitosis and requires binding of viral genomes to host mitotic chromosomes via L2 [38-40].

Following nuclear entry, the genome is thought to be rapidly amplified to around 50-100 copies per cell [8]. As HPV does not encode a polymerase, this is achieved via co-option of the host DNA replication machinery, a process mediated by the viral E1 and E2 proteins [41, 42]. Episomal copy number is then maintained in basal cells, where virus protein expression remains minimal due to E2-mediated repression of the 
a

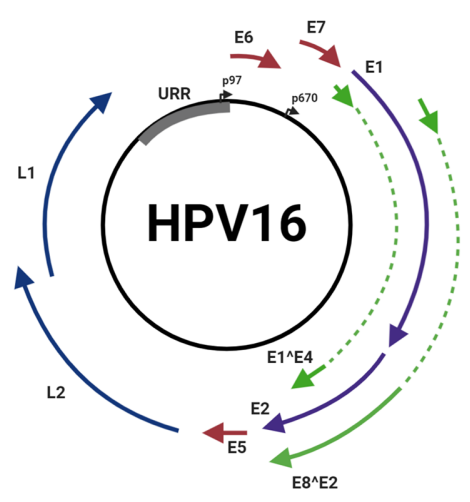

C

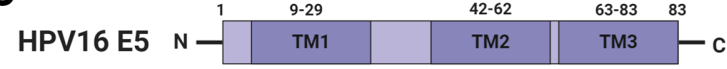
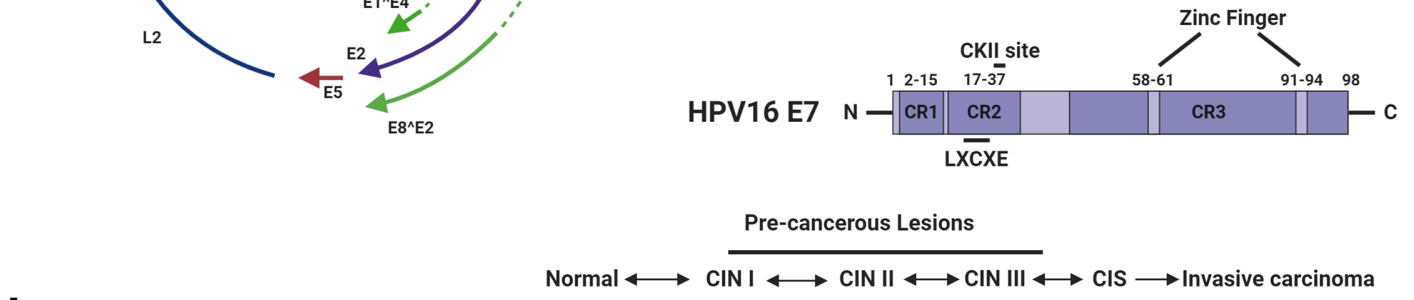

b

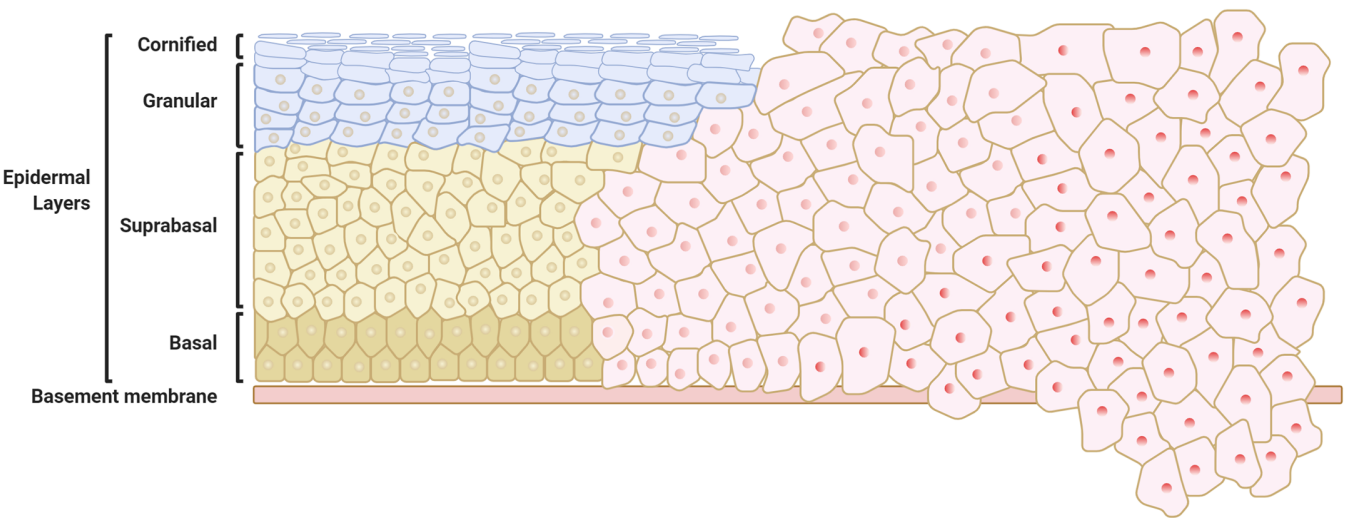

Fig. 1. Dysregulation of the HPV life cycle can contribute to carcinogenesis. (a) HPV16 genome organization, displaying the position of viral transcripts. The URR, and early and late promoters are also highlighted. (b) Schematic representation of the development of cervical cancer. Cancer typically progresses from cervical intraepithelial neoplasia (CIN). CIN is classified using a three-stage system based on the proportion of the epithelium displaying abnormalities. CIN1 represents a transient HPV infection, whilst CIN2 and 3 represent a persistent HPV infection with a risk of progression to cancer. Epithelial layers are outlined on the left. CIS, carcinoma in situ. (c) HPV16 oncoprotein structure. Numbers refer to amino acid positions. TM, transmembrane domain; PBM, PDZ-binding motif; CR, conserved region; CKII, casein kinase II. Figure created using BioRENDER.com.

p97/p105 early promoter, aiding in avoidance of the immune response [43]. As the infected basal cell divides, one daughter cell remains in the basal layer and acts as an episomal reservoir whilst the other begins to migrate up through the epithelial layers. Here, expression of the viral oncoproteins E5, E6 and E7 delays terminal differentiation and prevents cell-cycle exit in order to provide a suitable environment for further genome amplification, which occurs in an extended G2-like environment $[44,45]$. As the oncoproteins do not possess any intrinsic enzymatic activity, this must be achieved by interacting with and modulating the activity of host cellular factors.

The life cycle is completed in the uppermost layers of the epithelium after terminal differentiation has occurred and requires expression of the viral $\mathrm{L} 1, \mathrm{~L} 2$ and $\mathrm{E} 1 \wedge \mathrm{E} 4$ proteins. Virion assembly occurs in the nucleus after importation of the L1 and L2 capsid proteins, followed by release of newly formed virus particles from the epithelial surface [46].

\section{Dysregulation of the HPV life cycle during transformation}

As is clear from the above section, carcinogenesis is not the default result of the HPV life cycle. Rather, it can be a consequence of a non-productive infection, and represents a 'dead-end' for the virus, as despite the synthesis of viral proteins, progeny virions are not produced. In most cases, HR-HPVs typically only cause a short-lived infection, which is cleared over a period of a few months; however in the event of a persistent infection, where the host immune system fails to detect and clear the virus efficiently, transformation may take place (Fig. 1b) [8].

The most important factor required for cancer progression is dysregulation of viral oncoprotein expression, prolonging their pro-proliferative effects upon the host cell [11]. Increased oncoprotein expression is often associated with integration of viral episomes into the host genome and can 
confer a selective growth advantage to cells [47, 48]. Indeed, the majority of HPV16-associated cervical cancer cases and almost all HPV18-associated cases contain an integrated genome, as do $70 \%$ of HPV-positive (HPV+) head and neck squamous cell carcinoma (HNSCC) cases $[49,50]$. Frequently, oncoprotein overexpression is due to disruption of the E2 ORF during integration, preventing E2-mediated repression of E6 and E7 expression [43, 48]. This can also be achieved through methylation of E2 binding sites within the viral URR [51]. Further, integration often results in hybrid virus-host transcripts, which are more stable than viral transcripts, thus potentially enhancing oncoprotein expression [52].

Significantly, given that the majority of HR-HPV infected cells do not progress to cancer, oncoprotein expression is necessary yet not sufficient for transformation [6]. It follows, therefore, that other genetic insults to host oncogenes and tumour suppressors are also required for progression to occur $[49,50]$. Despite this, the cellular environment created by the activities of the HR-HPV oncoproteins discussed in the following sections of this review - that of rapid cell-cycle progression, abrogated cell-cycle checkpoints and genomic instability - is highly conducive to the acquisition of such host genetic aberrations.

\section{THE E5 ONCOPROTEIN}

The E5 protein is a poorly understood viral protein of between 8 and $9.5 \mathrm{kDa}$ expressed by a subset of HPV types, including the high-risk HPV16, 18 and 31 [53]. E5 is a membrane integrated, highly hydrophobic protein and HPV16 and 18 E5 proteins contain three putative $\alpha$-helical structures that function as transmembrane domains (TMDs) (Fig. 1c). The lack of antibody reagents for HPV E5 has hampered investigations into its biological functions during infection [53]; however, overexpression studies have elucidated some important aspects of E5 biology. HPV E5 primarily localizes to the endoplasmic reticulum and the Golgi apparatus, with a small proportion also observed at the perinuclear region and plasma membrane [54]. Furthermore, HPV16 E5 has been shown to oligomerize both in vitro and in cells [55]; however, this has not been observed in HPV-infected cells due to the lack of suitable reagents discussed above.

As an early gene, E5 plays an important role during the productive viral life cycle. Using HPV genomes lacking a functional E5 ORF, studies indicate that HPV16, HPV18 and HPV31 E5 proteins have no apparent role in regulating viral genome maintenance or the proliferative ability of undifferentiated keratinocytes [56-58]. In contrast, E5 has a clear role in the differentiation-dependent stages of the HPV life cycle. Our group demonstrated that HPV18 E5 is required for unscheduled DNA synthesis in suprabasal cells, but not for genome amplification or the expression of late viral proteins [56]. Interestingly, defective expression of the late viral protein E1^E4 was reported for HPV31 E5 knock out (E5KO) genomes, yet no $\mathrm{E} \wedge^{\wedge} \mathrm{E} 4$ defect has been observed with the corresponding HPV16 and HPV18 E5KO genomes [56-58]. These data therefore suggest that E5 proteins from different
HPV types may have distinct roles during the productive viral life cycle.

The major transforming proteins of HPV are E6 and E7; however, for bovine papillomavirus (BPV) type 1, the major transforming protein appears to be E5 [59]. One critical function of BPV1 E5 is activation of the platelet-derived growth factor receptor (PDGFR), resulting in downstream mitogenic signalling, enhanced DNA synthesis and transformation $[60,61]$. This occurs via direct binding of BPV1 E5 to the PDGFR $\beta$ isoform [62]. In contrast, there is no evidence for BPV4 E5 activation of growth-factor receptors; rather it disrupts the expression and activity of key cell-cycle regulators such as cyclin A and p27 $7^{\mathrm{KIP} 1}$ [63]. Significantly, HPV E5 also does not bind to or activate the PDGFR, and HPV E5 proteins alone were found to be weakly oncogenic in comparison to HPV E6 and E7 in transgenic mouse models where the oncoproteins were expressed under the control of the epithelial specific keratin-14 (K14) promoter [64]. Furthermore, the expression of E5 is not detected in all HPV+ tumours, suggesting its contribution to transformation may rather be in the modulation or enhancement of E6 and E7 functions [65-67]. Indeed, E5 was demonstrated to enhance the oncogenic abilities of HPV16 E7 in primary baby-rat kidney cells [66], whilst in K14 transgenic mouse models, tumour formation was greater in mice expressing HPV16 E5/E6 or E5/E7, when compared with E6 or E7 alone [67]. Interestingly, tumour formation in mice expressing E5 alone was only observed after treatment with oestrogen, an important driver of cervical carcinogenesis, indicating that E5 may promote, rather than initiate, tumourigenesis [67].

These studies have prompted investigations into how HPV E5 contributes to oncogenesis (Fig. 2). Many studies have demonstrated that $\mathrm{E} 5$ binds to a range of host proteins, several of which have been shown to function in the dysregulation of critical biological pathways associated with cellular transformation (Table 1).

\section{Induction of cell proliferation}

Early studies suggested that, similar to the BPV1 E5 protein, one of the primary oncogenic functions of HPV E5 is the modulation of growth-factor signalling $[22,23]$. To this end, HPV E5 has been shown to bind the growth-factor receptor ErbB4, promoting cell proliferation [68]. However, E5-mediated EGFR activation has been the most extensively studied aspect of its biological functions [22-24]. Our group demonstrated that HPV18 E5-induced EGFR signalling is critical in maintaining unscheduled DNA synthesis and cell-cycle progression during keratinocyte differentiation, suggesting that this function of E5 may contribute to both the virus life cycle and E5-mediated tumourigenesis [56]. Interestingly, E5 activation of the EGFR is essential for E5-induced hyperplasia and cellular transformation in vivo [69]. Further, recent studies have demonstrated that the activation of EGFR by E5 can also induce the expression of the growth-factor receptor c-Met, a potent oncogene [70]. 


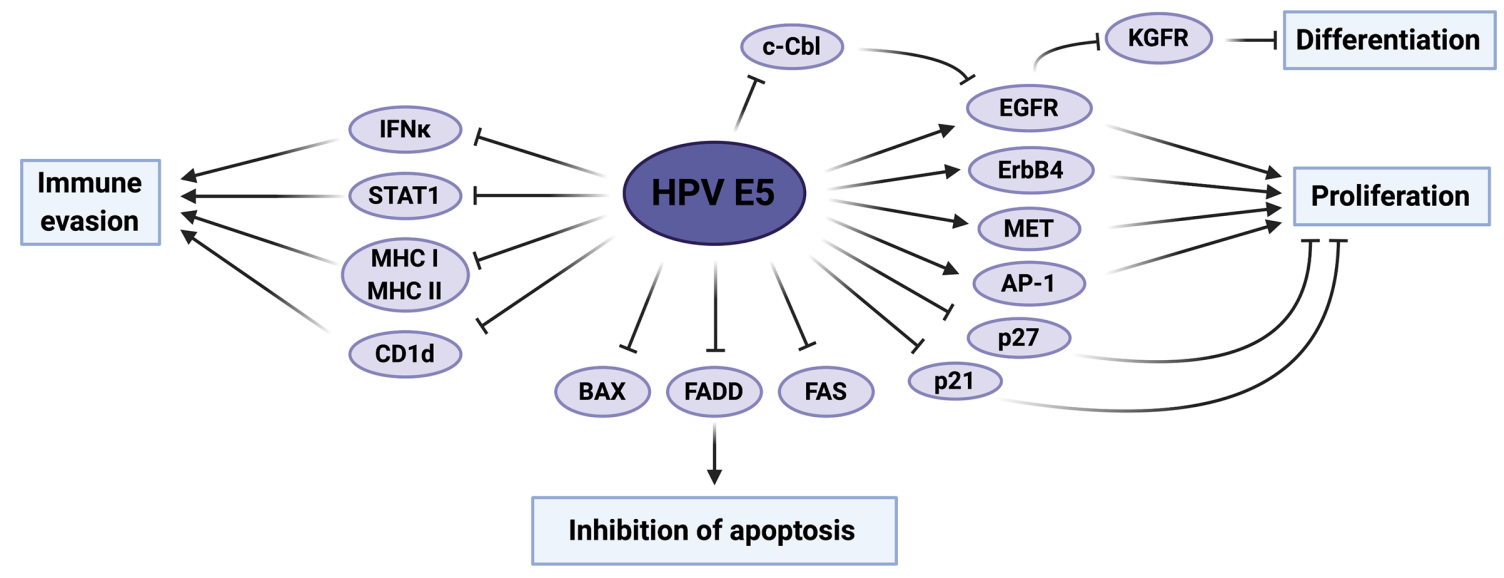

Fig. 2. Summary of HPV E5 activities which contribute towards host-cell transformation. The host proteins and pathways reported to be modulated by HPV E5 are displayed, as well as the functional impact these have on the host cell. STAT, signal transducer and activator of transcription; MHC, major histocompatibility complex; EGFR, epidermal growth factor receptor; KGFR, keratinocyte growth factor receptor; AP-1, activator protein 1; FADD, Fas-associated protein with death domain. Figure created using BioRENDER.com.

Several mechanisms for EGFR activation by HPV E5 have been proposed. Initially, the interaction of E5 with the 16K subunit of the vacuolar $\mathrm{H}^{+}$-ATPase (v-ATPase) was suggested to abrogate its role in the endosomal acidification process, resulting in reduced EGFR degradation after growth-factor stimulation [71]. However, subsequent studies have shown that this may not be the case [72, 73]. HPV16 E5 has also been shown to bind directly to the EGFR, but this is not thought to be critical for E5-mediated EGFR activation [74]. HPV E5 can also disrupt the interaction between the EGFR and the E3 ligase c-Cbl, reducing EGFR ubiquitination and degradation, thereby enhancing mitogenic signalling [75].
Our lab has demonstrated an additional mechanism of EGFR activation induced by HPV16 E5. As mentioned above, HPV16 E5 forms oligomers and detailed biochemical studies demonstrated that E5 can function as a virus-encoded ion channel, a so-called viroporin [76, 77]. Interestingly, well-characterized broadly acting inhibitors of other viroporins, such as rimantadine, also inhibit E5 viroporin activity resulting in reduced E5-mediated EGFR activation [78]. Furthermore, this function of E5 was also shown to be important for the expression of mediators of cell-cycle progression, suggesting that viroporin activity may play a role in malignant transformation [78]. Further studies are

Table 1. Host proteins known to interact with HPV E5

\begin{tabular}{|c|c|c|c|c|}
\hline Protein name & HR-HPV & LR-HPV & Proposed function & Reference \\
\hline A4 & + & $?$ & Increased proliferation & [95] \\
\hline Bap31 & + & $?$ & Increased proliferation & {$[96]$} \\
\hline Calnexin & + & $?$ & Immune evasion & {$[88]$} \\
\hline EGFR & + & ? & Increased proliferation & {$[74]$} \\
\hline ErbB4 & + & $?$ & Increased proliferation & {$[68]$} \\
\hline EVER1 & + & $?$ & Promotes AP- 1 activation & [277] \\
\hline EVER2 & + & $?$ & Promotes AP-1 activation & [277] \\
\hline YIPF4 & + & + & Unknown & [279] \\
\hline $\mathrm{ZnT}-1$ & + & $?$ & Promotes AP- 1 activation & {$[277]$} \\
\hline
\end{tabular}

+ , interaction confirmed; ?, binding ability not analysed. 
required to identify the exact mechanism of EGFR activation by HPV E5.

As well as enhancing EGFR signalling, HPV16 E5 also downregulates expression of the anti-proliferative keratinocyte growth-factor receptor (KGFR) [56, 79]. Interestingly, E5-mediated downregulation of KGFR, also known as FGFR2b, is associated with an upregulation of its spliceisoform FGFR2c [80]. This isoform is highly expressed in mesenchymal-like cells and the induction of FGFR2c by HPV16 E5 promotes epithelial-mesenchymal transition (EMT), an important event in the progression to malignant transformation [80].

In addition to the modulation of growth-factor receptor signalling, HPV E5 can also promote cell proliferation by other mechanisms. Early studies demonstrated that HPV11 and HPV 16 E5 can induce expression of the proto-oncogene c-Jun, a key driver of cell proliferation [81]. Furthermore, whilst HPV16 E5 promoted mitogen-activated protein kinase (MAPK) signalling in response to EGF in the mouse 3T3 fibroblast cell line, it also induced EGF-independent activation of MAPK via protein kinase C (PKC) signalling [82]. HPV E5 can also directly regulate cell-cycle progression via the inhibition of $\mathrm{p} 21^{\mathrm{WAF} 1 / \mathrm{CIP} 1}$ and $\mathrm{p} 27^{\mathrm{KIP} 1}[83,84]$.

\section{Inhibition of apoptosis}

An important hallmark of cancer cells is the ability to avoid apoptosis, particularly in response to death ligands. As a virus, HPV induces stress upon infected cells and the abrogation of cell-cycle checkpoints during infection promotes apoptosis. HPV has therefore evolved efficient mechanisms to prevent cell death. HPV16 E5 contributes towards this by promoting the proteasomal degradation of the pro-apoptotic Bcl-2 family member BAX upon reactive oxygen species (ROS)-induced apoptosis [85]. Furthermore, HPV16 E5 can prevent FasLand TNF-related apoptosis-inducing ligand (TRAIL)-induced apoptosis by downregulating expression of the Fas receptor and inhibiting recruitment of Fas-associated protein with death domain (FADD) to form the death-induced signalling complex (DISC) [86]. HPV16 E5 can also inhibit the apoptotic response to ultraviolet (UV)-B radiation; this requires E5-dependent activation of EGFR and downstream signalling through phosphatidylinositol 3-kinase (PI3K) and extracellular signal-regulated kinase 1/2 (ERK1/2) [87].

\section{E5-mediated immune evasion}

E5 has also been shown to modulate the immune response to infection by interfering with the expression or trafficking of several critical immune receptors, including Major Histocompatibility Complex (MHC) class I, MHC class II and CD1d [88-92]. The cell-mediated arm of the adaptive immune response, which plays an essential role in the detection of virus-infected cells, functions by recognizing foreign protein epitopes on the surface of an infected cell in complex with MHC class I. E5 proteins from several HPV types (2a, 16 and 83 ) have been shown to specifically downregulate HLA-A and HLA-B, abrogating their cell-surface expression and inhibiting T-cell recognition of HPV-infected cells $[89,90]$. HPV16 E5 can bind directly to MHC class I via its first TMD, which may act to retain MHC class I within the Golgi apparatus, preventing its onward trafficking to the cell surface $[93,94]$. Other mechanisms, such as the formation of a ternary complex with MHC class I and the chaperone calnexin, and/or a quaternary complex between HPV E5, MHC class I, Bap31 and A4, have also been speculated as possible explanations for the retention of MHC class I in the Golgi $[88,95,96]$. HPV E5 can additionally impede cellsurface expression of MHC class II and CD1d, suggesting that HPV E5 promotes subversion of the immune system via multiple mechanisms [91, 92].

The E5 oncoprotein is also capable of dysregulating interferon (IFN) signalling. HPV16 E5 can suppress the expression of STAT1, thus preventing downstream IFN-stimulated gene (ISG) transcription [97]. Furthermore, E5 silences expression of IFNא, a key keratinocyte-specific IFN involved in antiviral immunity; although the exact mechanism for this remains to be determined, silencing results in abrogated ISG expression [97]. Interestingly, the effects on IFNא expression were found to be, at least in part, dependent upon E5-induced EGFR signalling.

Recent data has suggested a potential role for E5 viroporin activity in the modulation of the host immune response. In a mouse model of HNSCC, HPV16 E5 expression resulted in a downregulation of MHC class I and this provided resistance to anti-programmed death-ligand 1 (anti-PD-L1) immunotherapy [98]. However, co-treatment with the viroporin inhibitor rimantadine sensitized tumours to anti-PD-L1 treatment, suggesting that $\mathrm{E} 5$ viroporin activity is responsible for the resistance to these therapies and could hence be therapeutically targeted using the currently available inhibitors [98].

\section{THE E6 ONCOPROTEIN}

E6 was first suspected to be an oncoprotein after analysis of cervical tumours and cervical cancer-derived cell lines revealed that the E6 ORF was retained during viral-genome integration and was highly expressed [99]. Follow-up experiments in human mammary epithelial and rat primary kidney cells confirmed that E6 possessed intrinsic transforming activities [100, 101]. Despite sharing some activities with their high-risk counterparts, low-risk E6 proteins are unable to induce transformation in primary cells [102]. Interestingly, studies have demonstrated that E6 and E7 likely cooperate in inducing tumour formation: E7 drives early carcinogenesis whilst E6 accelerates progression towards malignancy [103]. In support of this, both the E6 and E7 ORFs were found to be required in the context of the full viral genome for the immortalization of primary human keratinocytes [104].

E6 proteins are approximately 150 amino acids long and contain two zinc-binding motifs formed by two pairs of CXXC sequences, which are essential for the activities of E6 (Fig. 1c) [105]. Solving of the E6 structure by NMR revealed 


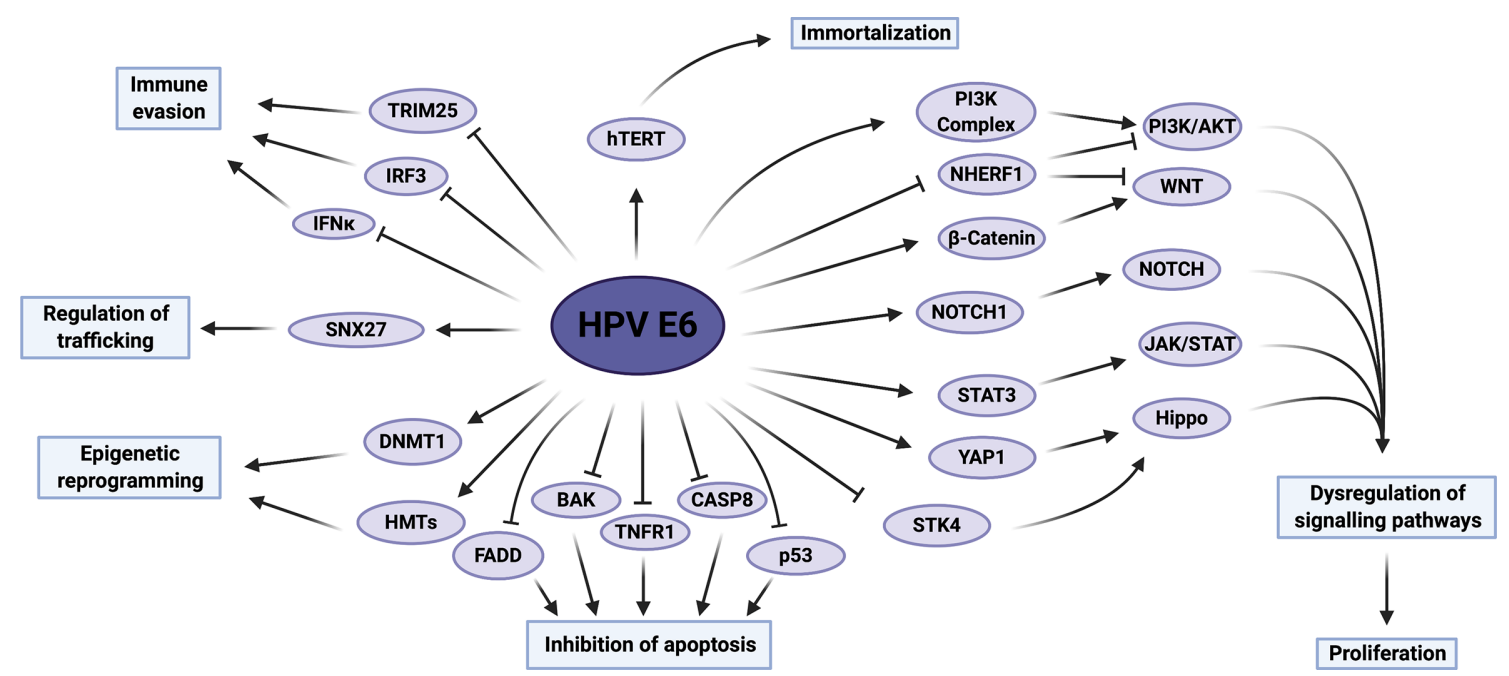

Fig. 3. Summary of HPV E6 activities which contribute towards host-cell transformation. The host proteins and pathways reported to be modulated by HPV E6 are displayed, as well as the functional impact these have on the host cell. hTERT, human telomerase reverse transcriptase; PI3K, phosphatidylinositol 3-kinase; NHERF1, Na+/ $\mathrm{H}^{+}$exchange regulatory factor 1; STAT, signal transducer and activator of transcription; JAK, Janus kinase; YAP1, Yes-associated protein 1; STK4, serine/threonine-protein kinase 4; CASP8, caspase-8; TNFR1, tumour necrosis factor receptor 1; BAK, Bcl-2 homologous antagonist/killer; FADD, Fas-associated protein with death domain; HMTs, histone methyltransferases; DNMT1, DNA methyltransferase 1; SNX27, sorting nexin 27; IRF3, IFN regulatory factor 3; TRIM25, tripartite motif-containing protein 25. Figure created using BioRENDER.com.

that the protein has two zinc-finger domains termed E6N and $\mathrm{E} 6 \mathrm{C}$, each formed of a three-stranded $\beta$-sheet and two short helices, connected by a short linker helix [106, 107]. Further, high-risk E6 proteins contain a C-terminal PDZ (PSD-95/DLG/ZO-1) binding motif (PBM) formed of an $\mathrm{X}-\mathrm{S} / \mathrm{T}-\mathrm{X}-\mathrm{V} / \mathrm{L}$ sequence (Fig. 1c) [108]. E6 is able to target a multitude of host cellular factors and perturb host signalling pathways despite a lack of intrinsic enzymatic activity; these are summarized in Fig. 3, Table 2.

\section{Blockade of pro-apoptotic signalling}

The best-studied function of HR-HPV E6 is the degradation of the p53 tumour suppressor protein in order to disrupt pro-apoptotic signalling [109]. p53 is a sequence-specific DNA binding protein that serves as an effector of DNA damage and is mutated or inactivated in over half of all human cancers [110]. It is capable of inducing cell-cycle arrest, cellular senescence and apoptosis through transcriptional regulation in response to a diverse range of stresses, and is itself under exquisite control by a number of mechanisms, primarily by the E3 ubiquitin ligase mouse double minute 2 homologue (MDM2). Under normal cellular conditions, p53 undergoes rapid turnover due to binding of MDM2 and subsequent ubiquitination-dependent proteasomal degradation. Cellular stress-induced phosphorylation of $\mathrm{p} 53$ precludes binding of MDM2, thus permitting transcriptional activation of target genes [110]. HR-HPV E6 can interact with the host E6-associated protein (E6AP), a HECT domain-containing E3 ubiquitin ligase, by binding to its conserved LXXLL motif [17]. This allows the formation of a ternary complex with $\mathrm{p} 53$, which leads to its proteasomal degradation, thereby inhibiting p53-mediated apoptosis [18].

Importantly, E6-induced degradation does not totally deplete the host cell of p53, and low-risk E6 does not demonstrate an ability to degrade p53. HPV E6 proteins have therefore evolved additional degradation-independent mechanisms of inhibiting p53 signalling. E6 can prevent the acetylation of p53 by the related acetyltransferases $\mathrm{p} 300$ and CBP (CREB-binding protein) via the formation of a p53-E6-p300/CBP complex $[111,112]$. E6 also inhibits the function of ADA3, which similarly promotes p53 acetylation and thus stabilization; although in contrast to $\mathrm{p} 300 / \mathrm{CBP}$, this is achieved via degradation [113]. Direct binding of both high-risk and low-risk E6 proteins to the $\mathrm{C}$-terminus of $\mathrm{p} 53$ has also been reported, as well as sequestration of p53 in the cytoplasm; these act to prevent $\mathrm{p} 53$ from interacting with DNA $[105,114]$. Whilst the primary aim of these activities is to abrogate pro-apoptotic signalling in response to HPV E7-induced hyperproliferation, in the context of a persistent infection the prolonged loss of p53 function allows the accumulation of genetic mutations and thus contributes to cancer progression.

In addition to targeting p53, E6 targets other proteins involved in apoptosis. This includes binding to the host proapoptotic protein $\mathrm{Bcl}-2$ homologous antagonist/killer (BAK) in order to suppress intrinsic apoptosis signalling. Similar to p53, E6 complexes with E6-AP to target BAK for degradation $[115,116]$. Furthermore, E6 also dysregulates the extrinsic apoptosis pathway, which transmits extracellular apoptotic stimuli from the cell surface, through interactions with FADD 
Table 2. Host proteins known to interact with HPV E6

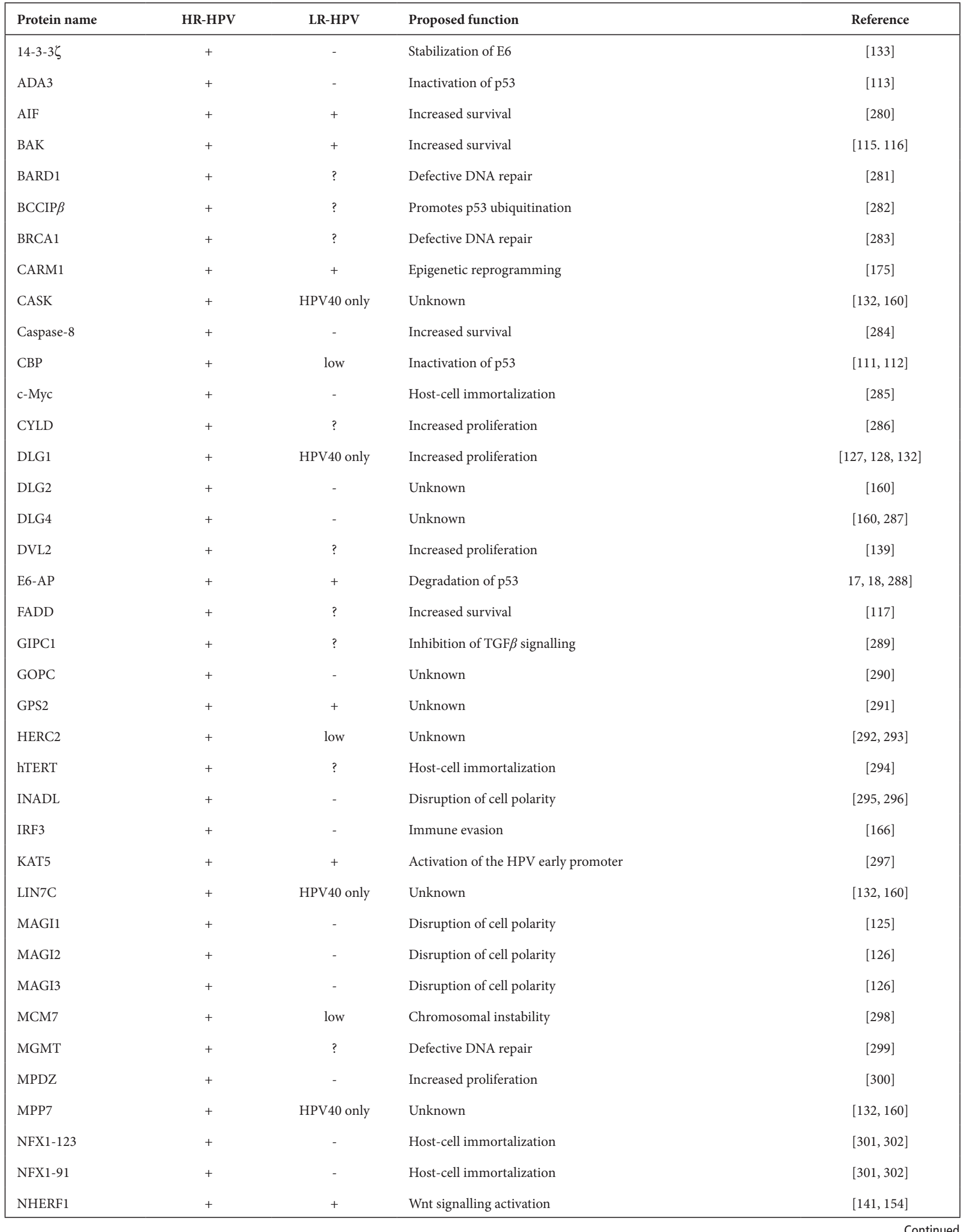


Table 2. Continued

\begin{tabular}{|c|c|c|c|c|}
\hline Protein name & HR-HPV & LR-HPV & Proposed function & Reference \\
\hline p53 & + & low & Inhibition of apoptosis & {$[17,109,114,303,304]$} \\
\hline PML & + & + & Inhibition of PML-induced senescence & {$[305]$} \\
\hline PRMT1 & + & + & Epigenetic reprogramming & {$[175]$} \\
\hline PTPN3 & + & - & Increased proliferation & {$[160,308]$} \\
\hline $\mathrm{RCN} 2$ & + & - & Unknown & [309] \\
\hline SCRIB & + & - & Disruption of cell polarity; increased E6 expression & {$[124,132,160,310]$} \\
\hline SET7 & + & + & Epigenetic reprogramming & {$[175]$} \\
\hline TAX1BP3 & + & - & Increased cell motility & {$[313]$} \\
\hline TNFR1 & + & $?$ & Increased survival & [119] \\
\hline TRIM25 & + & + & Immune evasion & {$[168]$} \\
\hline TSC2 & HPV16 only & - & Increased mTORC1 signalling & {$[155]$} \\
\hline TYK2 & + & low & Immune evasion & {$[167]$} \\
\hline USP15 & + & + & Immune evasion & {$[168,220]$} \\
\hline XRCC1 & + & - & Defective DNA repair & {$[314]$} \\
\hline $\mathrm{ZO}-2$ & + & - & Increased cell migration & {$[132]$} \\
\hline
\end{tabular}

+, interaction confirmed; -, no interaction recorded; low, limited binding detected; ?, binding ability not analysed.

and caspase- 8 , leading to their degradation $[117,118]$. As these proteins are required to potentiate signalling from all death receptors, this allows the virus to inhibit extrinsic signalling from multiple receptors at once. HPV16 E6 has also been shown to directly bind the C-terminus of the transmembrane death receptor tumour necrosis factor receptor 1 (TNFR1), further disrupting pro-apoptotic signalling [119].

\section{Interaction with PDZ proteins}

A property unique to the E6 oncoproteins of HR-HPVs is the presence of a C-terminal PBM [120]. This motif permits binding to a range of host proteins which possess PDZ domains, a protein-protein interaction motif of $\sim 90$ amino acids in length. An interaction with E6 has been confirmed for at least $19 \mathrm{PDZ}$ proteins to date, although this represents only a fraction of the $\sim 200$ host PDZ proteins [108]. Despite this, the range of proteins possessing PDZ domains clearly allows E6 to regulate multiple aspects of the hostcell environment. Significantly, p53 degradation-defective HR-HPV E6 proteins are still capable of immortalizing cells, but those defective in binding PDZ partners are unable to induce epithelial hyperplasia, underlining the importance of modulating the activity of host PDZ proteins [121, 122]. Interestingly, several of the PDZ proteins confirmed to bind HPV E6, including SCRIB, discs large homologue 1 (DLG1), $\mathrm{Na}^{+} / \mathrm{H}^{+}$exchange regulatory factor 1 (NHERF1) and the MAGI family of proteins, are regulators of cell polarity and cell-cell contacts [123-128]. The interaction with E6 results in the proteasomal degradation and/or mislocalization of the PDZ proteins, hence disrupting cell polarity, a common characteristic of malignant cells. E6 also targets sorting nexin 27 (SNX27), utilizing the PDZ domain to dysregulate trafficking of proteins such as glucose transporter 1 (GLUT1), essential for glucose uptake, thus disrupting cellular homeostasis and proliferation [129]. Furthermore, our lab recently demonstrated that HR-HPV E6 proteins promote host cell proliferation and survival in a PBM-dependent manner via the activation of c-Jun N-terminal kinase 1/2 (JNK1/2) [130]. Taken together, these observations have led to the hypothesis that targeting of PDZ proteins contributes significantly to HPV-induced transformation [131]. Indeed, the number of PDZ proteins bound by E6 correlates strikingly with the potential for oncogenicity: although binding to DLG1 is 


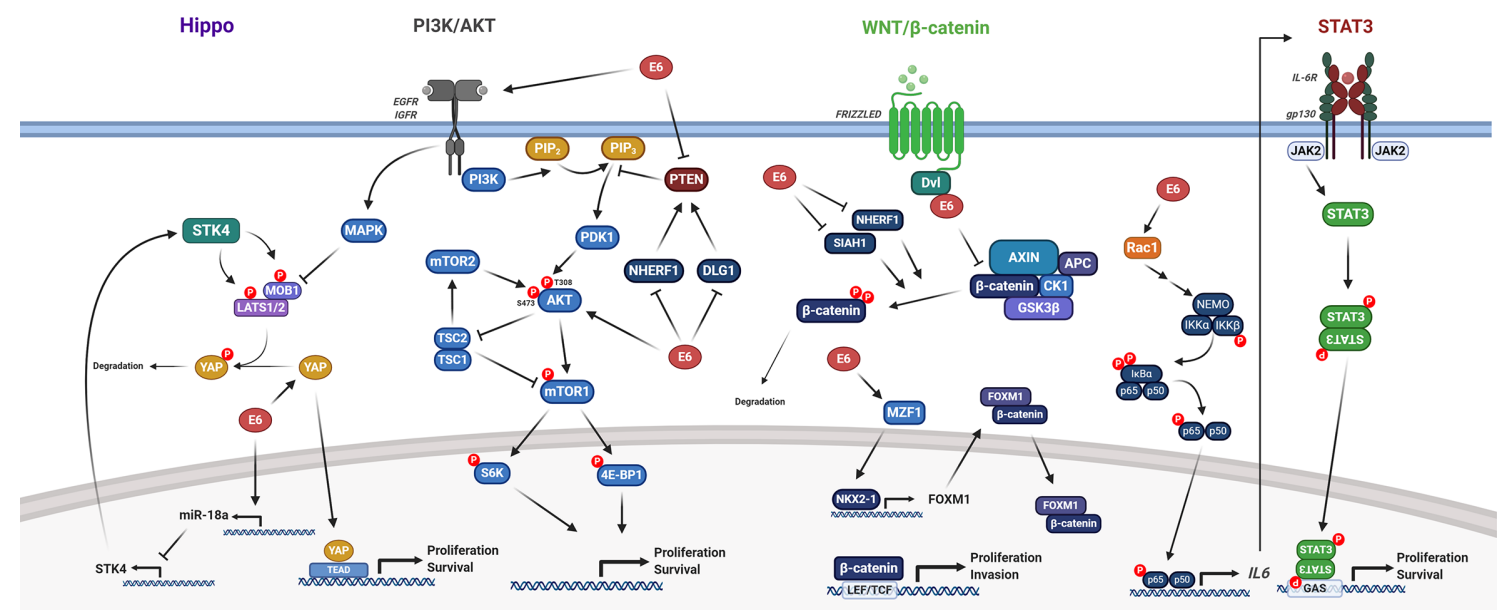

Fig. 4. HPV E6 modulation of host signalling pathways. Summary of the mechanisms by which HR-HPV E6 dysregulates the host Hippo, PI3K/AKT, Wnt/ $\beta$-catenin and JAK/STAT signalling pathways. See text for details. Figure created using BioRENDER.com.

shared by all HR-HPV E6 proteins, only those of HPV16 and 18 are capable of binding SCRIB [132]. Binding of E6 to PDZ proteins can be abrogated by phosphorylation of a threonine residue within the PBM of E6 by AKT in the case of HPV16, or, for HPV18, by PKA [133].

\section{Host-cell immortalization}

E6 can promote oncogenesis through host-cell immortalization due to activation of the telomerase complex [134]. Increased telomerase activity and the subsequent lengthening of telomeres permits indefinite proliferation by circumventing the onset of senescence associated with excessive telomere shortening. Expression of HR-HPV E6 is necessary and sufficient for telomerase activation: this is achieved via upregulated expression of the catalytic subunit of telomerase, human telomerase reverse transcriptase (hTERT) $[135,136]$. Significantly, low-risk E6 proteins do not activate telomerase [137]. The mechanisms by which E6 promotes hTERT expression are complex and multi-layered (see [134] for a review): it hijacks several host factors, including specificity protein 1 (Sp1) and $\mathrm{c}-\mathrm{Myc}$ to activate transcription, whilst also modulating the transcriptional repressors upstream stimulating factor 1 and 2 (USF1 and USF2).

\section{Dysregulation of host signalling networks}

E6 achieves many of its oncogenic functions by dysregulating a multitude of host signalling pathways (Fig. 4). Collectively, this acts to drive proliferation of host cells, typically by modulating the expression of downstream target genes associated with cell growth and survival. The pathways reported to be hijacked by E6 are outlined in turn in this section.

\section{Wnt signalling pathway}

The Wnt pathway is a highly conserved signalling axis implicated in the regulation of development, but is also commonly dysregulated in cancer [138]. The main effector of canonical Wnt signalling is $\beta$-catenin which, in the absence of Wnt ligands, is rapidly phosphorylated by glycogen synthase kinase 3 beta (GSK3 $\beta$ ), targeting it for ubiquitin-mediated degradation. Conversely, binding of a Wnt ligand to its cognate receptor leads to the stabilization and nuclear accumulation of $\beta$-catenin and the transcription of genes associated with proliferation [138]. HPV16 E6 can bind directly to Dishevelled 2 (DVL2), a protein which impedes formation of the $\beta$-catenin degradation complex; this promotes $\beta$-catenin nuclear accumulation [139]. Additionally, evidence indicates that the E6/E6-AP complex can further stabilize $\beta$-catenin [140]; subsequent studies indicate this is likely associated with the ability of E6/E6-AP to interact with and induce the proteasomal degradation of NHERF1, a negative regulator of canonical Wnt signalling [141]. E6 is also reported to upregulate forkhead box protein M1 (FOXM1) expression, a $\beta$-catenin binding partner, which promotes its nuclear localization, via a myeloid zinc finger 1 (MZF1)/NK2 homeobox 1 (NKX2-1) signalling axis [142]. Further, cells in which expression of E6 and E7 is repressed display enhanced seven in absentia homologue 1 (SIAH1) expression, a protein implicated in $\beta$-catenin degradation, suggesting the oncoproteins may, to some degree, cooperate in dysregulating the Wnt pathway [143]. Unconstrained activation of the Wnt pathway leads to uncontrolled promotion of biological processes such as proliferation, differentiation and tumourigenesis.

\section{Notch signalling pathway}

The Notch pathway is a highly conserved signalling pathway essential for the regulation of proliferation, cell fate and differentiation [144]. The pathway is activated upon Notch ligand-receptor binding at the surface of adjacent cells, which induces a cascade of cleavage events to release the Notch intracellular domain (NICD) from the membrane-bound receptor. NICD translocates to the nucleus to stimulate transcription of target genes in concert with the coactivator Mastermindlike protein 1 (MAML1). Aberrant activation of Notch has been reported in a wide variety of cancers, and intriguingly 
both tumour suppressive and oncogenic roles for the pathway have been proposed, but the role of Notch signalling during HR-HPV infection and cervical cancer is less clear [145]. The Notch1 receptor has been observed to be transcriptionally upregulated in HPV16 E6-containing keratinocytes and also to increase with cervical cancer progression $[146,147]$. Additionally, expression of both Notch receptors and ligands is upregulated in a significant proportion of HNSCC cases [148]. Conversely, a different study identified specific downregulation of the Notch1 receptor in HPV+ cervical cancer cell lines and invasive cervical carcinoma biopsies, and showed that reintroduction of NCID abrogated HPV oncoprotein expression [149]. Clearly, therefore, much remains to be understood regarding the role of Notch signalling in HPV-driven carcinogenesis.

\section{PI3K/AKT/mTOR signalling pathway}

The PI3K/AKT/mTOR signalling pathway is a key regulator of proliferation, metabolism and motility, and one of the most frequently dysregulated pathways in human cancers [150]. Given this essential role in the regulation of proliferation, it is unsurprising that HPV E6 dysregulates the pathway at multiple points. A key stage in this signalling axis involves the activation of class I PI3Ks by receptor tyrosine kinases (RTKs), allowing the phosphorylation of phosphatidylinositol 4,5-bisphosphate (PIP2) to generate phosphatidylinositol 3,4,5-trisphosphate (PIP3), a short-lived second messenger. This can be reversed, and the pathway thereby inactivated, through the phosphatase and tensin homolog (PTEN), a lipid phosphatase and bona fide tumour suppressor. Early reports demonstrated that HPV18 E6 expression was sufficient to induce increased PI3K and AKT phosphorylation [151]. This was hypothesized to be, at least in part, associated with the ability of HPV E6 to bind and degrade the PDZ domaincontaining protein DLG1, a binding partner of PTEN, which promotes its stabilization [151, 152]. Furthermore, NHERF1, in addition to its role as a negative regulator of the Wnt pathway, can also inhibit PI3K signalling by promoting the recruitment of PTEN [153]. Therefore, E6-induced degradation of NHERF1 also contributes to uncontrolled PI3K/AKT signalling [154].

One of the many downstream targets of AKT is the mammalian target of rapamycin complex 1 (mTORC1). mTORC1 kinase activity is indirectly inhibited via the tuberous sclerosis complexes $1 / 2$ (TSC1/2), which in turn are negatively regulated by AKT phosphorylation [150]. It was initially thought mTORC1 could be activated by HPV16 E6-induced degradation of TSC2 in an E6-AP-dependent manner $[155,156]$. However, subsequent studies cast doubt upon these findings as no evidence for TSC2 degradation was apparent; rather mTORC1 activation was concluded to be achieved in an AKT-dependent manner [157]. Later, hyperactivity of a range of RTKs, including the EGFR, the insulin receptor (INSR) and the insulin-like growth factor receptor (IGF1R), was confirmed to contribute towards PI3K/AKT/mTOR pathway activation in HPV16 E6-expressing foreskin keratinocytes [158].

\section{Hippo signalling pathway}

The Hippo signalling pathway is a key pathway in organ homeostasis and is dysregulated in many types of cancer [159]. Activation of the canonical Hippo pathway results in the induction of a kinase cascade, ultimately leading to the phosphorylation of the downstream transcriptional regulators Yes-associated protein 1 (YAP1) and transcriptional coactivator with PDZ-binding motif (TAZ). This promotes binding of 14-3-3 proteins to YAP1/TAZ and hence their cytoplasmic retention, ultimately resulting in proteasomal degradation. However, when the Hippo pathway is inactive, YAP1/TAZ localize to the nucleus and interact with the TEA domain (TEAD) family of transcription factors, leading to transcription of genes involved in cell proliferation and survival.

HR-HPV is capable of dysregulating the Hippo signalling pathway at several stages. E6 has been shown to upregulate YAP1 protein levels by shielding it from proteasomal degradation in a manner dependent on its PBM, resulting in the nuclear accumulation of YAP1 in both cervical tumours and HPV-containing keratinocytes [19, 160]. Indeed, YAP1 overexpression alone is sufficient to induce cervical dysplasia [161]. Additionally, our studies have demonstrated that expression of the serine/threonine-protein kinase 4 (STK4), a key upstream negative regulator of YAP1/TAZ activity, is significantly downregulated in HPV+ cervical cancer [162]. Together, these activities lead to uncontrolled oncogenic YAP1 activity, contributing to the increased proliferation and survival necessary for tumourigenesis.

\section{JAK/STAT signalling pathway}

The Janus kinase/signal transducer and activator of transcription (JAK/STAT) pathway is a key signalling axis associated with the regulation of embryonic development, stem-cell maintenance and the inflammatory response. Further, dysregulation of JAK/STAT signalling has also been shown to promote cancer progression, immune evasion and metastasis [163]. Pathway activation occurs upon binding of cytokines, interleukins and growth factors to a number of transmembrane receptors. This in turn results in activation of JAKs, followed by the recruitment, phosphorylation and activation of STAT proteins. Subsequently, STAT dimers translocate to the nucleus and bind to specific promoter sequences, leading to the transcription of target genes.

STAT3 drives proliferation in stratified epithelia and is essential for the maintenance of stemness. Studies in our lab have demonstrated that STAT3 phosphorylation is increased in HPV-containing keratinocytes in an E6-dependent manner and that this is required for episome maintenance in undifferentiated cells as well as the continued proliferation of suprabasal cells [20]. A number of studies have confirmed that STAT3 phosphorylation is also increased in cervical cancer [164]; this is achieved through increased NFKB signalling and autocrine/paracrine activation of STAT3 by the pro-inflammatory cytokine interleukin-6 (IL-6) [21]. Importantly, we have shown that STAT3 activity, as well as that of the upstream kinase JAK2, is essential for proliferation and survival of cervical cancer cells $[21,165]$. 


\section{E6-mediated immune evasion}

Evidence also suggests that E6 is capable of modulating the immune response to infection. HR-HPV E6 proteins interact with a component of the innate immune response: IFN regulatory factor 3 (IRF3) [166]. This interaction is thought to prevent the transactivation of IFN $\beta$ expression and hence the induction of ISGs. Furthermore, HPV18 E6 has been demonstrated to directly interact with and impair activation of the non-receptor tyrosine kinase 2 (TYK2), thus inhibiting the induction of JAK/STAT signalling [167]. Disruption of the immune response can also be achieved via dysregulation of the RIG-I pathway: E6 proteins from several high-risk types bind to TRIM25 and USP15, two key activators of RIG-I, promoting the ubiquitination and degradation of TRIM25 and ultimately inhibiting the activation of RIG-I signalling [168]. Furthermore, E6 inhibits transcription of the keratinocyte-specific IFNא, in addition to E5-induced methylation of its promoter, to prevent activation of antiviral ISGs and pattern recognition receptors (PRRs) [97, 169].

\section{Epigenetic reprogramming of host cells}

Significant alterations to host chromatin modification patterns, including DNA methylation and histone acetylation/ methylation, are observed during HPV infection. Aberrant DNA methylation at promoter regions is an important way in which loss of tumour suppressor gene expression can occur during carcinogenesis and has been reported in cervical cancer [170]. One of the major mechanisms associated with this likely involves oncoprotein activation of DNMT1, the methyltransferase responsible for maintenance of DNA methylation levels. Indeed, HPV infection has profound effects upon the host methylome: 8000 and 10000 genes were demonstrated to have altered DNA methylation levels, either increased or decreased, in primary keratinocytes harbouring episomal HPV16 and HPV18 genomes, respectively [171]. E6 indirectly increases DNMT1 expression through the degradation of p53 [172]. p53 negatively regulates DNMT1 expression by binding in concert with $\mathrm{Sp} 1$ to the DNMT1 promoter but in the absence of $\mathrm{p} 53$, Sp1 acts to enhance DNMT1 expression [173]. Whilst the full functional impact of E6-mediated modulation of the host methylome remains to be understood, it has been shown that E6 expression leads to hypermethylation and hence silencing of the death associated protein kinase 1 (DAPK1) promoter, a tumour suppressor that is a key mediator of IFN $\gamma$-induced, as well as apoptotic, cell death [174].

Additionally, E6 can affect host chromatin structure via the dysregulation of histone-modifying enzymes. Both high-risk and low-risk E6 proteins interact with the histone methyltransferases coactivator associated arginine methyltransferase 1 (CARM1), protein arginine methyltransferase 1 (PRMT1) and SET7, resulting in inhibition of their enzymatic activity [175]. Together, this provides another mechanism by which HPV modulates p53 function: CARM1 and PRMT1 are required to activate transcription from p53-responsive promoters, whilst SET7 has an additional function in methylating, and hence stabilizing, p53 [175]. Importantly, however, loss of the activity of these methyltransferases is likely to have wider impacts upon cellular functions due to global changes in gene transcription, which remain to be elucidated.

\section{Targeting of non-coding RNAs}

Emerging evidence indicates that the HPV oncoproteins are also capable of targeting non-coding RNA (ncRNA) species, including microRNAs (miRNAs), long non-coding RNAs (lncRNAs) and circular RNAs (circRNAs), in order to manipulate the host-cell environment. All three of these ncRNA types have been documented to be dysregulated in HPV infection and cervical cancer, with effects that promote proliferation and contribute to delayed differentiation (see [176] for a review).

miRNAs are short, $\sim 22$ nucleotide non-coding RNA species expressed in nearly all eukaryotes [177]. miRNAs typically downregulate gene expression by binding to the 3'UTR of target transcripts, promoting their cleavage. Despite the numerous studies evaluating the expression of miRNAs in cervical neoplasia and cervical cancer tissue biopsies, the mechanisms behind the observed changes in expression are often poorly understood. However, HR-HPV E6 has been demonstrated to directly regulate the expression of a collection of miRNAs. Among these, downregulation of the tumour suppressive miRNAs miR-34a and miR-218 has been reported in both HPV+ cell lines and HPV+ cervical lesions [178, 179]. Conversely, E6-induced enhancement of miR-20a and miR-20b expression likely contributes towards increased proliferation and invasion of cervical cancer cells $[180,181]$. Furthermore, studies in our group indicate that oncoprotein-induced expression of the oncogenic miR-18a contributes towards the dysregulation of Hippo signalling discussed previously by silencing STK4 expression [162]. Importantly, we demonstrated that reintroduction of STK4, or transfection of an antagomir to inhibit miR-18a, led to a reduction in proliferation [162].

LncRNAs are RNA molecules greater than 200 nucleotides long and possess many of the same structural features of mRNAs but lack a recognizable ORF [182]. They can localize to both the nuclear and cytoplasmic compartments of the cell and have many modes of action, including inhibition of miRNAs via sponging, epigenetic regulation of gene expression and stabilization of mRNA transcripts [182]. LncRNAs have been documented to promote cancer development through their regulation of proliferation, apoptosis and invasion, and could also serve as cancer biomarkers. Cervical cancer is no exception to this, and a number of lncRNAs have been demonstrated to be dysregulated during progression [176]. For example, expression of the cervical carcinoma expressed PCNA regulatory (CCEPR) lncRNA is markedly increased in cervical cancer, and expression directly correlates with tumour size and poor prognosis [183]. Expression of CCEPR was later shown to be driven by HPV16 E6 in a p53 degradation-independent manner [184]. The 


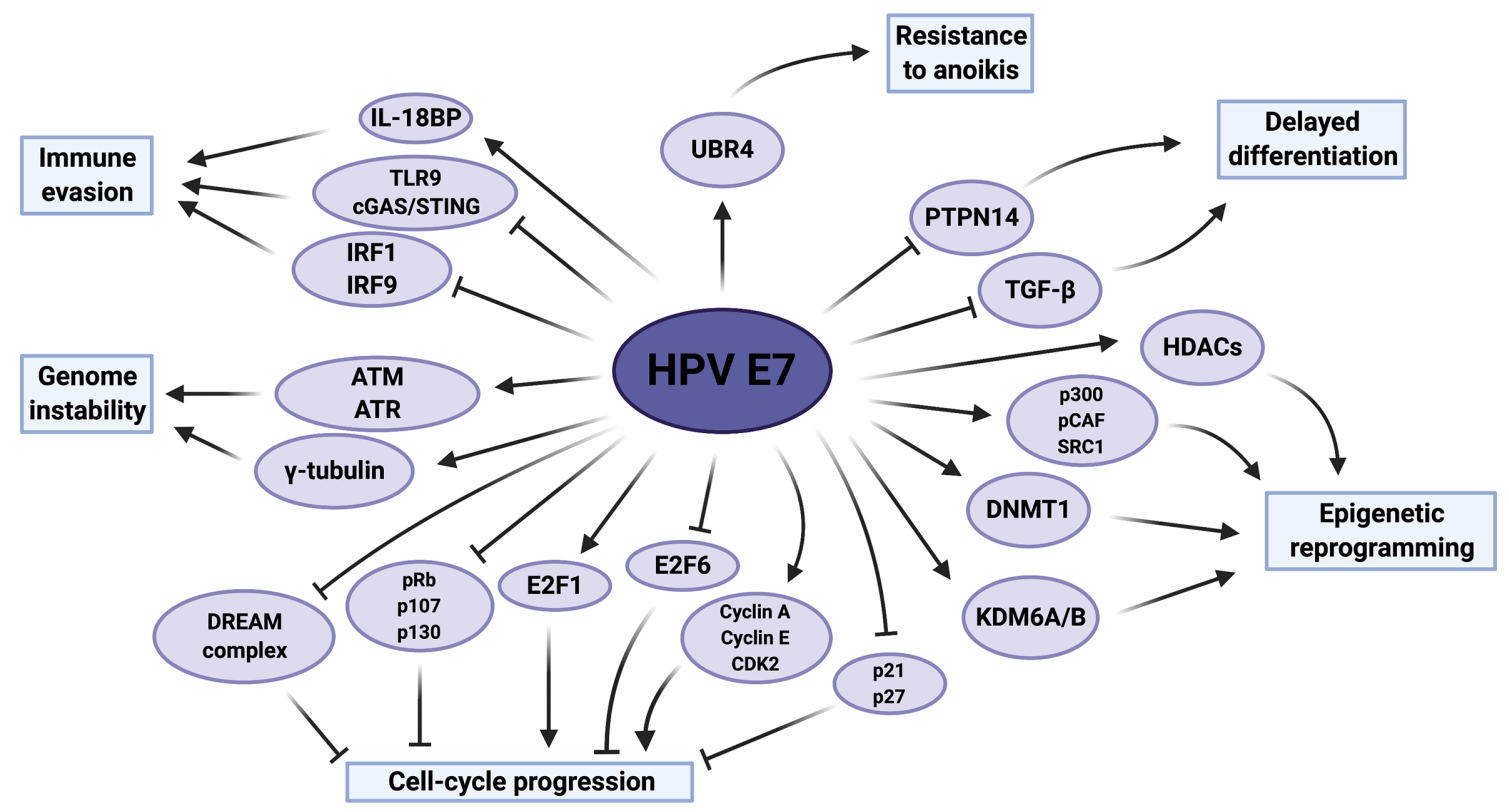

Fig. 5. Summary of HPV E7 activities which contribute towards host-cell transformation. The host proteins and pathways reported to be modulated by HPV E7 are displayed, as well as the functional impact these have on the host cell. PTPN14, protein tyrosine phosphatase non-receptor type 14; TGF $\beta$, transforming growth factor beta; HDACs, histone deacetylases; SRC1, steroid receptor coactivator 1; DNMT1, DNA methyltransferase 1; KDM6A/B, lysine demethylase 6A/B; CDK2, cyclin-dependent kinase 2; pRb, retinoblastoma protein; DREAM, dimerization partner, pRb-like, E2F and multi-vulval class B; ATM, ataxia-telangiectasia mutated; ATR, ataxia-telangiectasia and Rad3related; IRF, IFN regulatory factor; TLR9, Toll-like receptor 9; cGAS, cyclic GMP-AMP synthase; STING, stimulator of IFN genes; IL-18BP, interleukin-18 binding protein. Figure created using BioRENDER.com.

expression of other lncRNAs, including FAM83H antisense RNA 1 (FAM83H-AS1) and H19, was also demonstrated to be increased in HPV16 E6-expressing primary keratinocytes, although precise mechanisms are yet to be elucidated [185].

\section{THE E7 ONCOPROTEIN}

The E7 protein is considered to be the major transforming protein of HR-HPVs and its continued expression is essential for carcinogenesis [186, 187]. Underlining its importance, sequencing of viral genomes has revealed remarkable amino acid sequence conservation of the E7 protein in high-grade cervical neoplasia and cervical cancer specimens [188]. The protein is $\sim 100$ amino acids long and possesses two conserved regions (CR1 and CR2) at its N-terminus, which show significant similarity to other DNA virus oncoproteins, including adenovirus E1A and simian virus 40 (SV40) large tumour antigen (Fig. 1c) [189]. Within CR2 lies the conserved LXCXE motif necessary and sufficient for binding to $\mathrm{pRb}$, and a casein kinase II phosphorylation site [12, 190, 191]. The C-terminus of E7 is less well-conserved except for two CXXC zinc-binding motifs [186]. E7 possesses both nuclear localization and nuclear export signals (NLS and NES, respectively), suggesting that it shuttles between the cytoplasm and nucleus and has functions in both compartments [192]. Much like E6, the E7 oncoprotein is multifunctional (Fig. 5), and is reported to interact with numerous host proteins (Table 3 ).

\section{Targeting of the retinoblastoma protein (pRb) family of tumour suppressors}

The best-characterized function of E7 is dysregulating the G1/S-phase transition in order to promote increased proliferation by disrupting E2F transcription factor activity. The E2F transcription factors typically consist of an E2F subunit (E2F1-6) and a DP subunit (DP1-3), although two additional non-canonical family members, E2F7 and E2F8, have been reported (see [193] for a review). E2F transcription factors can be broadly divided into activators of transcription (E2F1, $2,3 a$ and $3 b$ ), which preferentially bind $p R b$, and repressors (E2F4-8). Within a naïve cell, phosphorylation of $\mathrm{pRb}$ by CDK2, CDK4 or CDK6 during G1 phase induces dissociation of E2Fs, leading to expression of genes necessary for S-phase progression. However, during infection, dysregulation of E2F transcription factors is achieved primarily by binding of E7 to $\mathrm{pRb}$ and the related pocket proteins $\mathrm{p} 107$ and $\mathrm{p} 130$ via the conserved LXCXE motif located within its CR2 domain [12-14]. Some evidence indicates that sequences within the C-terminus of E7 may also be required for $\mathrm{pRb}$ binding [194]. Binding of E7 disrupts pRb-E2F complexes, releasing E2Fs from repression and hence enabling the expression of E2Fdependent genes associated with cell-cycle progression such as cyclins $\mathrm{A}$ and $\mathrm{E}$, contributing towards S-phase re-entry in differentiating suprabasal keratinocytes [11]. Concurrently, binding of HPV E7 to p107 and p130 leads to disruption of the dimerization partner, pRb-like, E2F and multi-vulval 
Table 3. Host proteins known to interact with HPV E7

\begin{tabular}{|c|c|c|c|c|}
\hline Protein name & HR-HPV & LR-HPV & Proposed function & Reference \\
\hline AP-1 (c-Jun, JunB, JunD, c-Fos isoforms) & + & ? & Increased transforming ability & [317] \\
\hline ATM & + & $?$ & DDR activation & [233] \\
\hline B-Myb/MuvB complex & + & low & Increased proliferation & [318] \\
\hline BRG1 & + & - & Increased proliferation & [319] \\
\hline Calpain & + & ? & $\mathrm{pRb}$ destabilization & [200] \\
\hline Casein kinase II & + & + & Increased transforming ability & {$[190,191]$} \\
\hline CDK2 & + & + & Increased proliferation & {$[207,320]$} \\
\hline Cullin 1 & + & $?$ & Ubiquitin-mediated degradation of E7 & {$[323]$} \\
\hline Cullin 2 & HPV16 only & - & $\mathrm{pRb}$ degradation & {$[198,199]$} \\
\hline Cullin 3 & + & + & Unknown & [199] \\
\hline Cyclin A & + & + & Increased proliferation & {$[14,207]$} \\
\hline Cyclin E & + & + & Increased proliferation & {$[207,320]$} \\
\hline DNMT1 & + & $?$ & Altered host methylome & [246] \\
\hline DYRK1A & + & $?$ & Phosphorylation and stabilization of E7 & [324] \\
\hline Gelsolin & + & $?$ & Cytoskeletal rearrangements & {$[327]$} \\
\hline GRP78 & + & ? & Increased oncoprotein stability & {$[328]$} \\
\hline GSTP1 & + & $?$ & Increased survival & [329] \\
\hline HDAC1 & + & $?$ & Increased proliferation & {$[250]$} \\
\hline HDAC2 & + & $?$ & Increased proliferation & {$[250]$} \\
\hline HIF-1 $1 \alpha$ & + & + & Promotes angiogenesis & {$[330]$} \\
\hline HTRA1 & + & $?$ & Unknown & [331] \\
\hline IGFBP-3 & + & low & Increased survival & [332] \\
\hline IKKa & + & $?$ & Immune evasion & {$[323]$} \\
\hline $\operatorname{IKK} \beta$ & + & $?$ & Immune evasion & {$[333]$} \\
\hline IRF1 & + & + & Immune evasion & [226] \\
\hline IRF9 & + & $?$ & Immune evasion & {$[225]$} \\
\hline KCMF1 & + & + & Unknown & [199] \\
\hline MAP4 & HPV16 only & low & Deregulation of mitosis & {$[334]$} \\
\hline Miz-1 & + & + & Inhibition of p21 expression & {$[335]$} \\
\hline
\end{tabular}


Table 3. Continued

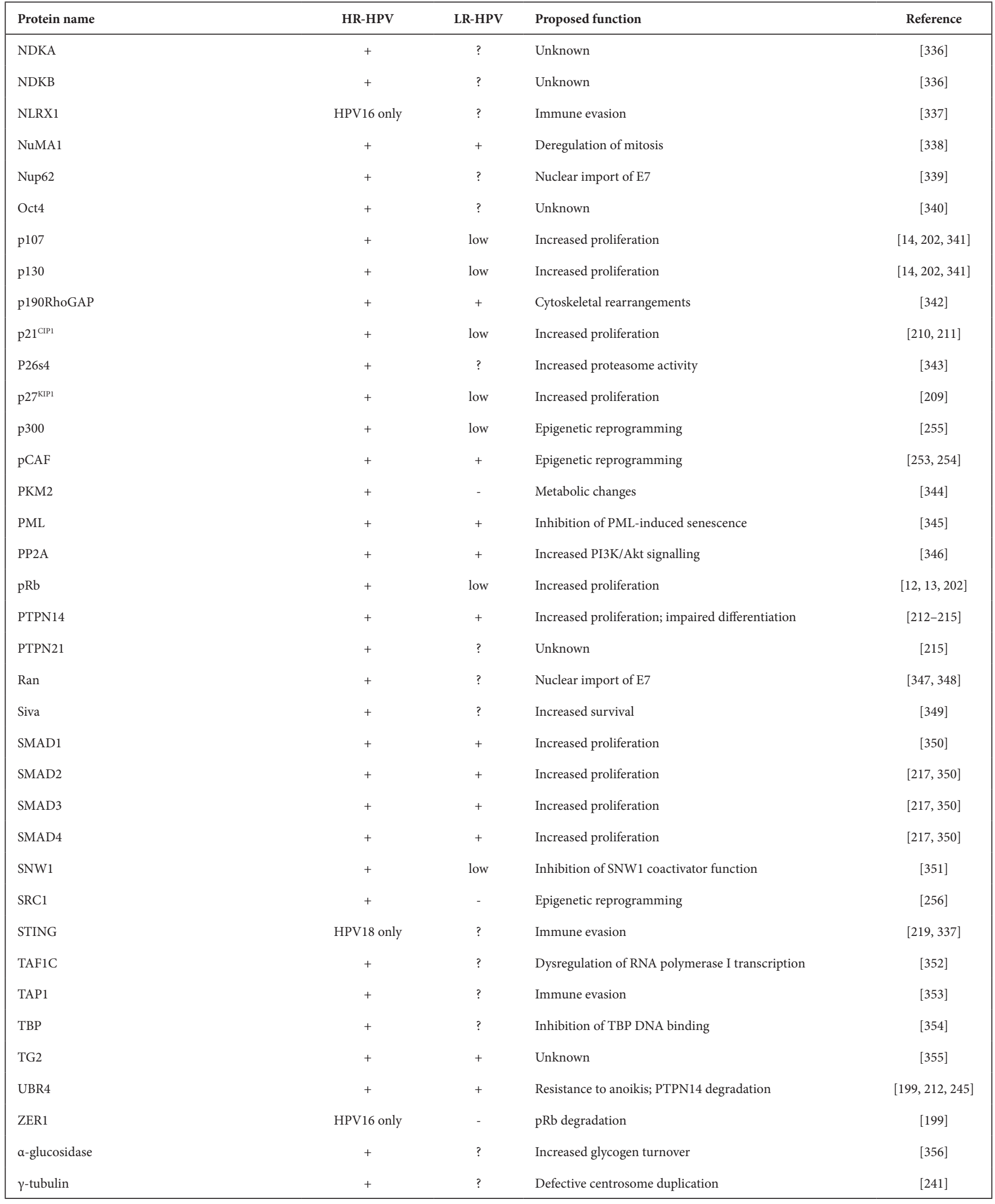

+, interaction confirmed; -, no interaction recorded; low, limited binding detected; ?, binding ability not analysed. 


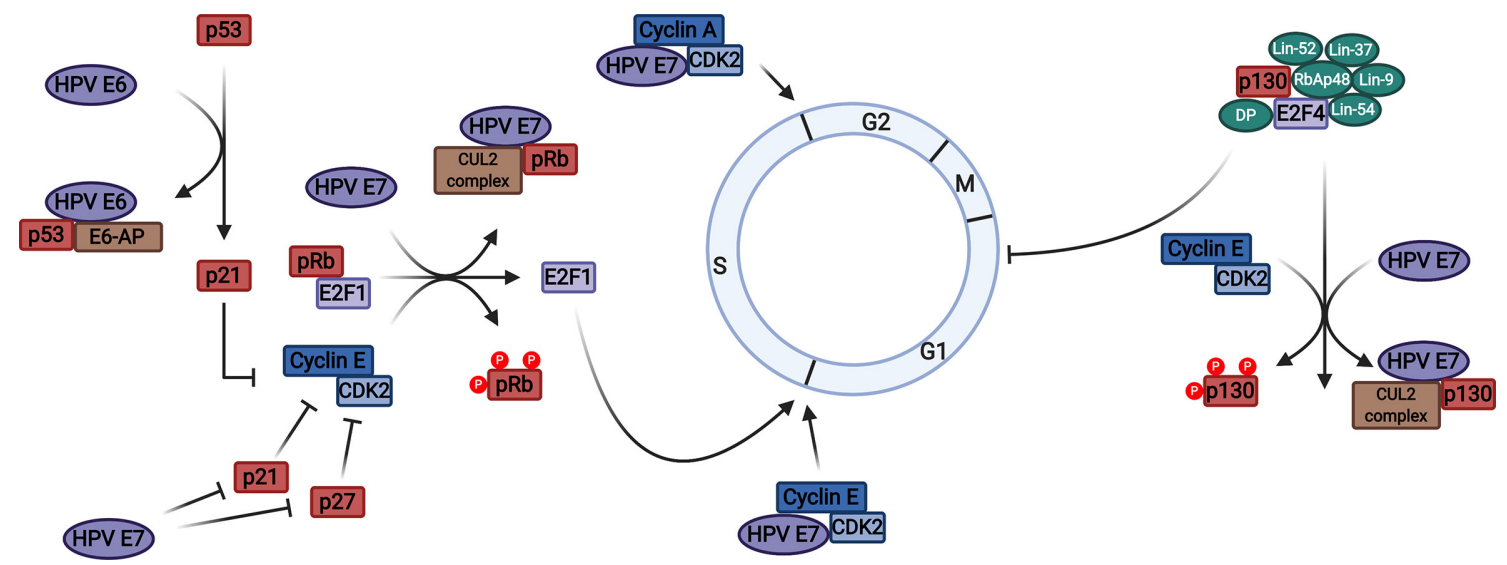

Fig. 6. Dysregulation of cell-cycle checkpoints by HPV E7. The mechanisms employed by HPV to include cell-cycle progression are illustrated. HPV E7 binds to and induces the degradation of the retinoblastoma protein (pRb) in a cullin 2 (CUL2) ubiquitin ligasedependent manner. This releases the E2F1 transcription factor from inhibitory complexes, permitting the expression of genes associated with S-phase progression. Degradation of the related pocket proteins $\mathrm{p} 107$ and $\mathrm{p} 130$ prevents inhibition of G1 progression by the DREAM complex. HPV E7 also binds directly to cyclins A and E, potentiating cyclin-dependent kinase 2 (CDK2) activity. Further, HPV E7 can suppress the activity of the CDK inhibitors p21 and p27, allowing increased cyclin/CDK phosphorylation of pRb and enhanced E2F1dependent transcription. HPV E6 also indirectly contributes towards cell-cycle progression: E6-associated protein (E6-AP)-dependent degradation of p53 prevents induction of p21 expression. Figure created using BioRENDER.com.

class B (DREAM) repressor complex, permitting a further enhancement in the expression of proliferative genes [195]. E7-pocket protein binding and S-phase entry is significantly enhanced by casein kinase II phosphorylation of serine-32 and -34 residues within the CR2 domain [196, 197].

Further, HR-HPV E7 proteins can target Rb family members for proteasomal degradation via a mechanism that requires binding to the cullin 2 ubiquitin ligase complex by E7 $[15,16,198,199]$. E7-induced degradation also requires cleavage of $\mathrm{pRb}$ by the protease calpain-1; this unmasks a $\mathrm{C}$-terminal unstructured region of $\mathrm{pRb}$, which acts as an efficient initiation region for degradation by the proteasome $[200,201]$. In contrast, low-risk E7 proteins have a significantly weaker affinity for the pocket proteins, which likely contributes to their lack of transforming activity [12]. Interestingly, only p130 degradation has been reported for the low-risk E7 proteins, suggesting that destabilization of this pocket protein is vital for the HPV life cycle yet dispensable for tumourigenesis [202].

\section{Other mechanisms underlying dysregulation of the G1/S cell-cycle checkpoint}

In addition to indirectly modulating E2F activity through targeting pRb, E7 also possesses other mechanisms of affecting $\mathrm{E} 2 \mathrm{~F}$ transcription factors. A direct interaction between E7 and E2F1 has been reported; this leads to a further increase in E2F-dependent gene expression [203]. A consequence of this is heightened expression of the repressive E2F6 transcription factor, which likely constitutes a feedback loop to prevent inappropriate expression of E2F1-dependent genes at other stages of the cell cycle [204]. E2F6 acts as a transcriptional repressor of E2F-responsive promoters by recruiting polycomb group $(\mathrm{PcG})$ complexes and histone methyltransferases
[205]. This negative feedback loop can be negated by binding of E7 to E2F6, leading to its inactivation [206].

E7 proteins are also able to dysregulate the G1/S-phase checkpoint in other ways. The activity of CDK2, a kinase crucial for S-phase entry and progression, is maintained via an interaction between its cognate cyclins (cyclin $\mathrm{E}$ and cyclin A) and E7 (Fig. 6) [207]. This is on top of already heightened cyclin A and E levels; their expression is regulated by E2Fs and is hence increased in E7-containing cells [208]. Further, the activities of the CDK inhibitors $\mathrm{p} 21^{\mathrm{CIP1}}$ and $\mathrm{p} 27^{\mathrm{KIP} 1}$, which are implicated in mediating keratinocyte differentiation via inducing a G1 cell-cycle arrest, are suppressed by E7 binding (Fig. 6) [209-211]. Together these mechanisms act to ensure the efficient S-phase re-entry of differentiating suprabasal epithelial cells.

\section{Impairment of differentiation}

In addition to its roles in driving proliferation, emerging evidence indicates that E7 may also play a role in impairing cellular differentiation. A diverse range of $\mathrm{E} 7$ proteins possess the ability to bind the non-receptor protein tyrosine phosphatase PTPN14, with HR-HPV E7 proteins additionally able to target it for proteasomal degradation using the UBR4 ubiquitin ligase [212, 213]. This loss of PTPN14 is critical in both delaying the epithelial differentiation programme and for cellular transformation, although evidence that this is achieved via modulation of Hippo pathway signalling remains controversial $[214,215]$. Interestingly, mutational analyses indicate that this constitutes one of the as yet poorly defined $\mathrm{pRb}$-independent functions of E7: regions in both $\mathrm{CR} 1$ and the C-terminus are necessary for formation of the E7/PTPN14/UBR4 complex. 
Manipulation of the TGF $\beta$ pathway by E7 may also contribute towards delaying epithelial differentiation. Expression of HPV16 E7 was shown to block TGF $\beta$-mediated suppression of c-Myc expression [216]. Mechanistically, one report claimed that the negative effects of TGF $\beta$ signalling on cell proliferation are abrogated by binding of HPV16 E7 to SMAD2, SMAD3 and SMAD4, thus preventing the association of SMADs with their DNA-binding elements [217].

\section{E7-mediated immune evasion}

Much like the other oncoproteins, E7 plays a role in immune evasion by HPV by targeting several stages of the cellular antiviral response. Indeed, recent evidence suggests that expression of both E6 and E7 is necessary to repress the innate immune response [218]. A key target for HPV are the host PRRs: direct binding of HPV18 E7 to STING, in a manner dependent on its LXCXE pRb-binding motif, results in inhibition of the cGAS-STING signalling axis, a major pathway involved in the recognition of exogenous DNA [219]. Signalling is further repressed in HPV+ cervical cancer cells via E7-induced upregulation of the $\mathrm{H} 3 \mathrm{~K}$ 9-specific DNA methyltransferase SUV39H1, leading to the suppression of cGAS and STING expression [220]. The histone demethylases KDM5B and KDM5C also participate in STING silencing by promoting removal of the activatory histone marker H3K4me3 [221]. Indeed, expression of KDM5B and STING are negatively correlated in HPV+ cancers [221]. Additionally, HPV16 E7 is able to promote the epigenetic silencing of the dsDNA sensor Toll-like receptor 9 (TLR9) via recruitment of KDM5B and the histone deacetylase HDAC1 to the TLR9 promoter [222]. Together, these measures act to prevent production of type I IFNs.

Immune signalling downstream of PRRs is also modulated by HPV. The transcription factor NFKB can be activated by numerous inflammatory stimuli and plays a major role in anti-viral immunity. Our group identified that E7 proteins from both high-risk and low-risk types prevented activation of NFKB signalling in primary keratinocytes, leading to reduced secretion of pro-inflammatory cytokines [223]. Further, we showed that E7 expression augments secretion of IL-18 binding protein (IL-18BP), an anti-inflammatory cytokine, in response to IFN $\gamma$ stimulation [224].

The IFN response is also suppressed via binding of E7 to IRF9, abrogating the expression of ISGs [225]. IRF1 is similarly thought to be targeted by high-risk E7 proteins: direct binding of HPV16 E7 to the C-terminus of IRF1 precludes binding to DNA and hence prevents expression of target genes such as IFN $\beta$ [226].

Furthermore, mouse models have demonstrated that HPV16 E7 expression results in a locally immunosuppressive environment where cytotoxic $\mathrm{T}$ lymphocyte function is significantly suppressed [227]. Mechanistically, this could be associated with reduced expression of the chemokine CXCL14, observed in both cervical cancer and HPV+ HNSCC tissue, due to E7-dependent promoter hypermethylation. Importantly, reintroduction of CXCL14 results in increased immune cell infiltration and suppresses tumour growth [228]. HPV E7 may also interfere with MHC class I surface expression, in addition to the role played by E5, in order to prevent NK cell-mediated killing [229].

\section{Replication stress and genomic instability}

Genomic instability is a hallmark of HPV + cancers, but is also frequently observed in premalignant cervical lesions [230]. Aberrant activation of the pRb-E2F pathway by HPV E7 and the ensuing unscheduled proliferation is sufficient to induce replication stress and genomic instability due to inadequate nucleotide pools [231, 232]. In support of this, HPV has been demonstrated to activate both the ATM (ataxia-telangiectasia mutated) and ATR (ataxia-telangiectasia and Rad3-related) DNA damage response (DDR) pathways, which are induced in response to DNA double-strand breaks and replication stress respectively [233-235]. Significantly, inhibition of either of these DDR signalling pathways has an adverse effect on viral genome amplification, suggesting that the virus has evolved to not only tolerate replication stress and the DDR, but to require them for its life cycle [233, 234]. Mechanistically, ATM activation is thought to be accomplished via a noncanonical route involving STAT5 signalling, which is at least in part E7-driven, and the acetyltransferase Tip60 [236, 237]. STAT5 is also implicated in driving the ATR-DDR response: HPV31 E7-induced STAT5 phosphorylation drives transcription of TopBP1, which subsequently binds and stimulates the kinase activity of ATR [234]. Importantly, the E1 helicase can similarly activate the DDR, and a recent study demonstrated that DDR activation occurs to the same extent in keratinocytes containing HPV16 genomes lacking functional E6 and E7 ORFs as with wild-type HPV 16 genomes, leading to the hypothesis amongst some that viral replication itself may also play a key role in DDR activation [218].

Intriguingly, a recent study suggests that DNA repair factors may be recruited away from host DNA towards viral genomes [232]. Indeed, several ATM-DDR signalling components, including ATM, $\gamma \mathrm{H} 2 \mathrm{AX}$, Chk2 and BRCA1, are localized to the sites of viral replication during an infection, perhaps to ensure high-fidelity genome replication [238]. This has led to the hypothesis that HPV episomes are shielded from the DNA damage ensuing from oncoprotein-induced replication stress, and that this may contribute to the DNA lesions and genetic instability in the host genome necessary for progression to cancer [232].

Other potential methods of inducing genomic instability have also been reported. Expression of HPV16 E7 can rapidly induce abnormal centrosome numbers in the host cell due to defective centrosome duplication, which in turn permits chromosome missegregation, aneuploidy and genomic instability $[239,240]$. Additionally, an association between E7 and $\gamma$-tubulin has been reported [241]. This purportedly delays the recruitment of $\gamma$-tubulin to centrosomes, further contributing to the subversion of centrosome duplication. 


\section{Resistance to anoikis}

Anoikis is a form of programmed cell death induced upon detachment from the extracellular matrix and resistance to anoikis (i.e. anchorage-independent growth) is a key hallmark of cancer cells [242]. Expression of BPV1 E7 was found to stimulate anchorage-independent cell growth and this correlated with its ability to bind UBR4 (also known as p600) $[243,244]$. An interaction between UBR4 and HPV16 E7 was also reported and indeed this ability to bind UBR4 was later found to be conserved across many HPV types $[199,245]$. Importantly, depletion of UBR4 in the presence of E7 inhibited anchorage-independent growth, suggesting this is likely a mechanism by which papillomaviruses dysregulate anoikis [243, 245]. More recently, the interaction between E7 and UBR4 was found to be required for PTPN14 degradation and that this contributes towards delaying keratinocyte differentiation, as discussed previously in this section [212-214]. However, PTPN14 knockout also reduced detachmentinduced cell death, perhaps indicating that targeting of this pathway by HPV may concurrently impact upon differentiation and anoikis [214].

\section{Epigenetic reprogramming of host cells}

In addition to the role played by E6 in dysregulating host epigenetic regulatory mechanisms, E7 can also induce significant alterations to cellular chromatin modification patterns. In some cases, the oncoproteins concurrently target the same host factor, such as the DNA methyltransferase DNMT1. Further to indirect activation of DNMT1 through E6-mediated p53 degradation, direct binding of HPV16 E7 to DNMT1 is sufficient to promote its enzymatic activity [246]. Moreover, the expression of DNMT1 and DNMT3B is reportedly increased in keratinocytes harbouring episomal HPV genomes [171].

E7 can additionally induce changes to cellular histone modifications. As discussed elsewhere in this review, modulating the expression and activity of histone-modifying enzymes can contribute to suppression of the host immune response [220-222]. In addition to this, a genome-wide reduction in levels of the repressive histone mark H3K27me3 has been reported in HPV16 E7-expressing keratinocytes due to transcriptional induction of the KDM6A and KDM6B lysine demethylases, whilst KDM6A expression is also significantly upregulated in HPV+ tumours [247, 248]. Cervical cancer cells have been demonstrated to be addicted to KDM6A: it is thought that loss of $\mathrm{H} 3 \mathrm{~K} 27$ trimethylation due to KDM6A activity promotes $\mathrm{p} 21^{\mathrm{CIP} 1}$ expression, which is required to survive E7-induced replication stress [249] .

E7 also interacts with histone deacetylases (HDACs), which function by removing acetyl groups from histone lysine residues, thus inducing chromatin remodelling and transcriptional repression [250]. Binding of E7 to HDACs was found to be essential for the HPV31 life cycle; this is likely associated with promoting S-phase progression in differentiating keratinocytes by increasing levels of E2F2-dependent transcription [251, 252]. Similarly, E7 can also associate with the histone acetyltransferases (HATs) p300, pCAF and SRC1 [253-256]. Whilst the biological relevance remains to be fully elucidated, it is clear that these interactions can result in reduced HAT activity.

\section{Targeting of non-coding RNAs}

Like E6, recent evidence indicates that HPV E7 can directly modulate the expression of multiple miRNAs, such as miR-203. The primary role of miR-203 is to promote epithelial differentiation by inducing cell-cycle exit, and as such levels of miR-203 increase in a differentiation-dependent manner [257]. Induction of the differentiation programme is achieved by downregulating expression of p63, a key driver of proliferation in epithelial tissue, which is commonly overexpressed in both HNSCC and cervical cancer [257, 258]. Suppression of miR-203 expression by E7 permits increased protein levels of $\Delta \mathrm{Np} 63$, the major epithelial $\mathrm{p} 63$ isoform, and hence contributes to delaying epithelial differentiation [258]. Other miRNAs purportedly targeted by E7 include miR-16, miR34b, miR-34c-5p and miR-486-5p, although the significance of these in relation to the HPV life cycle and cancer progression, as well as exact mechanisms, remain to be elucidated [259].

Co-regulation of miRNAs by E6 and E7 has also been reported: both oncoproteins contribute to the suppression of miR-424 in order to promote HPV genome amplification, whilst our data indicates that upregulation of the oncogenic miR-18a is necessary for transformation, as discussed previously $[162,260]$.

The expression of a number of lncRNAs can also be modulated by E7. Contrasting reports exist on the effect of E7 on expression of the HOX transcript antisense intergenic RNA (HOTAIR): one study indicated that HOTAIR was highly expressed in cervical cancer tissue and cell lines [261], whilst others suggest HOTAIR is in fact downregulated $[262,263]$. A physical interaction between HPV16 E7 and HOTAIR has also been reported [262]. This is hypothesized to disrupt normal HOTAIR function by impeding its binding to the Polycomb repressive complex 2 (PRC2) and the histone lysine demethylase KDM1 A, ultimately leading to the derepression of target genes. Other lncRNAs reportedly regulated by E7 include LINC01101 and LINC00277, both of which demonstrate low expression levels in cervical cancer specimens and are upregulated after siRNA silencing of E7 [264].

Interestingly, E7 may also act cooperatively with E6 to modulate $\operatorname{lncRNA}$ activity. Expression of thymopoietin pseudogene 2 (TMPOP2) was found to be upregulated in an oncoproteindependent manner in HPV+ cervical cancer cells as well as in HPV16 E6/E7 expressing keratinocytes [263, 265]. Depletion of TMPOP2 resulted in a decrease in proliferation due to arrest in G1 phase and a reduction in cyclin E and CDK2 expression [265]. Further, the oncoproteins have also been implicated in upregulating expression of the widely-studied metastasis associated lung adenocarcinoma transcript 1 (MALAT1) lncRNA [266]. Dysregulation of lncRNAs by HPV may also contribute towards delaying the onset of differentiation in keratinocytes: expression of HPV16 E6 and 
E7 in primary keratinocytes resulted in increased expression of differentiation antagonizing non-protein coding RNA (DANCR), whilst tissue differentiation-inducing non-protein coding RNA (TINCR) expression was suppressed [263]. High DANCR expression has similarly been reported in cervical cancer tissue, and depletion of DANCR significantly inhibited proliferation, migration and invasion, whilst siRNA knockdown of TINCR promoted cell growth [267, 268].

Finally, emerging evidence indicates that E7 may also dysregulate the expression of circRNAs. These are a collection of covalently closed ncRNAs produced by a unique splicing mechanism and function most commonly as sponges for miRNAs and in regulating gene transcription [269]. Microarray analysis demonstrated that upon E7 knockdown in CaSki cells, over 500 circRNAs were found to be altered in expression level [270]. However, the functional significance of this is yet to be understood. Other studies have also identified differentially expressed circRNAs in cervical cancer tissue, but whilst they have been linked to proliferation and cancer progression, it is as yet unclear whether changes in their expression are a direct result of oncoprotein activity [271-273]. Interestingly, HPV16 has been demonstrated to express its own circRNAs, one of which contains the entire E7 ORF and is hence termed circE7 [274]. Somewhat surprisingly, rather than functioning as a miRNA sponge, circE7 was found to be required for optimal E7 protein expression and circE7 depletion significantly impeded the proliferation of HPV+ cervical cancer cells [274].

\section{CONCLUSIONS}

The HPV oncoproteins E5, E6 and E7 have evolved to hijack many host signalling pathways in order to generate a cellular environment conducive for virus replication. This includes the widely studied functions of E6 and E7 in targeting p53 and $\mathrm{pRb}$, respectively, for proteasomal degradation. These, together with the other oncoprotein functions discussed in this review, act to stimulate proliferation, delay differentiation, inhibit apoptosis and evade immune detection. An undesired consequence of this is the acquisition of mutations in cellular genes, particularly in the context of dysregulated oncoprotein expression, which can facilitate transformation. Although much progress has been made in understanding the host pathways modulated by HPV, novel mechanisms continue to be elucidated. Gaining a thorough understanding of the cellular proteins and pathways subverted by HPV during infection, and in particular during carcinogenesis, will aid in the development of novel therapeutic agents.

\section{Funding information}

Work in the Macdonald lab is supported by Medical Research Council (MRC) funding (MR/ K012665 and MR/S001697/1). J.A.S. is funded by a Faculty of Biological Sciences, University of Leeds Scholarship. M.R.P. is funded by a Biotechnology and Biological Sciences Research Council studentship (BB/M011151/1) and E.L.M. was supported by a
Wellcome Institutional Strategic Support Fund (ISSF) (204825/Z/16/Z). The funders had no role in the preparation of the manuscript.

\section{Acknowledgements}

We are grateful to Dr Stephen Griffin (University of Leeds) for helpful comments on the manuscript. We apologise to authors whose work could not be cited due to space limitations.

\section{Author contributions}

Conceptualization - J.A.S., M.R.P., E.L.M., A.M., funding acquisition E.L.M., A.M., project administration - J.A.S., A.M., supervision - A.M., visualization - J.A.S., M.R.P., E.L.M., writing - original draft - J.A.S., M.R.P., E.L.M., writing - review and editing - J.A.S., E.L.M., A.M.

Conflicts of interest

The authors declare that there are no conflicts of interest.

References

1. Doorbar J, Egawa N, Griffin H, Kranjec C, Murakami I. Human papillomavirus molecular biology and disease association. Rev Med Virol 2015;25 Suppl 1:2-23.

2. Van Doorslaer K, Li Z, Xirasagar S, Maes P, Kaminsky D et al. The papillomavirus Episteme: a major update to the papillomavirus sequence database. Nucleic Acids Res 2017;45:D499-D506.

3. PaVE. The papillomavirus episteme. Available from: pave.niaid. nih.gov.

4. Cubie HA. Diseases associated with human papillomavirus infection. Virology 2013;445:21-34.

5. Durst M, Gissmann L, lkenberg H, zur Hausen H. A papillomavirus DNA from a cervical carcinoma and its prevalence in cancer biopsy samples from different geographic regions. Proc Natl Acad Sci U S A 1983;80:3812-3815.

6. Stanley M. Pathology and epidemiology of HPV infection in females. Gynecol Oncol 2010;117:S5-S10.

7. Munoz N, Bosch FX, de Sanjose S, Herrero R, Castellsague X et al. International agency for research on cancer multicenter cervical cancer study $G$. epidemiologic classification of human papillomavirus types associated with cervical cancer. $N$ Engl J Med 2003;348:518-527.

8. Graham SV. The human papillomavirus replication cycle, and its links to cancer progression: a comprehensive review. Clin Sci 2017;131:2201-2221

9. Bray F, Ferlay J, Soerjomataram I, Siegel RL, Torre LA et al. Global cancer statistics 2018: GLOBOCAN estimates of incidence and mortality worldwide for 36 cancers in 185 countries. CA Cancer J Clin 2018;68:394-424.

10. de Martel C, Plummer M, Vignat J, Franceschi S. Worldwide burden of cancer attributable to HPV by site, country and HPV type. Int J Cancer 2017;141:664-670.

11. Moody CA, Laimins LA. Human papillomavirus oncoproteins: pathways to transformation. Nat Rev Cancer 2010;10:550-560.

12. Munger K, Werness BA, Dyson N, Phelps WC, Harlow E et al. Complex formation of human papillomavirus E7 proteins with the retinoblastoma tumor suppressor gene product. Embo $J$ 1989:8:4099-4105.

13. Dyson N, Howley PM, Munger K, Harlow E. The human papilloma virus-16 E7 oncoprotein is able to bind to the retinoblastoma gene product. Science 1989;243:934-937.

14. Dyson N, Guida P, Munger K, Harlow E. Homologous sequences in adenovirus E1A and human papillomavirus E7 proteins mediate interaction with the same set of cellular proteins. J Virol 1992;66:6893-6902.

15. Boyer SN, Wazer DE, Band V. E7 protein of human papilloma virus-16 induces degradation of retinoblastoma protein through the ubiquitin-proteasome pathway. Cancer Res 1996:56:4620-4624.

16. Gonzalez SL, Stremlau M, He X, Basile JR, Munger K. Degradation of the retinoblastoma tumor suppressor by the human papillomavirus type 16 E7 oncoprotein is important for functional 
inactivation and is separable from proteasomal degradation of E7. J Virol 2001;75:7583-7591.

17. Huibregtse JM, Scheffner M, Howley PM. A cellular protein mediates association of p53 with the E6 oncoprotein of human papillomavirus types 16 or 18. Embo J 1991;10:4129-4135.

18. Scheffner M, Huibregtse JM, Vierstra RD, Howley PM. The HPV-16 E6 and E6-AP complex functions as a ubiquitin-protein ligase in the ubiquitination of p53. Cell 1993;75:495-505.

19. He C, Mao D, Hua G, Lv X, Chen X et al. The Hippo/YAP pathway interacts with EGFR signaling and HPV oncoproteins to regulate cervical cancer progression. EMBO Mol Med 2015;7:1426-1449.

20. Morgan EL, Wasson CW, Hanson L, Kealy D, Pentland I et al. Stat3 activation by $\mathrm{E} 6$ is essential for the differentiation-dependent HPV18 life cycle. PLoS Pathog 2018;14:e1006975.

21. Morgan EL, Macdonald A. Autocrine STAT3 activation in HPV positive cervical cancer through a virus-driven Rac1-NFKB-IL-6 signalling axis. PLoS Pathog 2019;15:e1007835.

22. Leechanachai $P$, Banks L, Moreau F, Matlashewski G. The E5 gene from human papillomavirus type 16 is an oncogene which enhances growth factor-mediated signal transduction to the nucleus. Oncogene 1992;7:19-25.

23. Pim D, Collins M, Banks L. Human papillomavirus type 16 E5 gene stimulates the transforming activity of the epidermal growth factor receptor. Oncogene 1992;7:27-32.

24. Straight SW, Hinkle PM, Jewers RJ, McCance DJ. The E5 oncoprotein of human papillomavirus type 16 transforms fibroblasts and effects the downregulation of the epidermal growth factor receptor in keratinocytes. J Virol 1993;67:4521-4532.

25. Smotkin D, Wettstein FO. Transcription of human papillomavirus type 16 early genes in a cervical cancer and a cancer-derived cell line and identification of the E7 protein. Proc Natl Acad Sci U S A 1986;83:4680-4684.

26. Grassmann K, Rapp B, Maschek H, Petry KU, Iftner T. Identification of a differentiation-inducible promoter in the E7 open reading frame of human papillomavirus type 16 (HPV-16) in raft cultures of a new cell line containing high copy numbers of episomal HPV-16 DNA. J Virol 1996;70:2339-2349.

27. Zheng ZM, Baker CC. Papillomavirus genome structure, expression, and post-transcriptional regulation. Front Biosci 2006;11:2286-2302.

28. Herfs M, Yamamoto Y, Laury A, Wang X, Nucci MR et al. A discrete population of squamocolumnar junction cells implicated in the pathogenesis of cervical cancer. Proc Natl Acad Sci U S A 2012;109:10516-10521.

29. Giroglou T, Florin L, Schafer F, Streeck RE, Sapp M. Human papillomavirus infection requires cell surface heparan sulfate. $J$ Virol 2001;75:1565-1570.

30. Aksoy P, Gottschalk EY, Meneses PI. Hpv entry into cells. Mutat Res Rev Mutat Res 2017;772:13-22.

31. Schelhaas M, Shah B, Holzer M, Blattmann P, Kuhling L et al. Entry of human papillomavirus type 16 by actin-dependent, clathrin- and lipid raft-independent endocytosis. PLoS Pathog 2012;8:e1002657.

32. Day PM, Thompson CD, Schowalter RM, Lowy DR, Schiller JT. Identification of a role for the trans-Golgi network in human papillomavirus 16 pseudovirus infection. J Virol 2013;87:3862-3870.

33. Bienkowska-Haba M, Williams C, Kim SM, Garcea RL, Sapp M. Cyclophilins facilitate dissociation of the human papillomavirus type 16 capsid protein L1 from the L2/DNA complex following virus entry. J Virol 2012;86:9875-9887.

34. DiGiuseppe S, Bienkowska-Haba M, Hilbig L, Sapp M. The nuclear retention signal of HPV16 L2 protein is essential for incoming viral genome to transverse the trans-Golgi network. Virology 2014:458-459:93-105.

35. Popa A, Zhang W, Harrison MS, Goodner K, Kazakov T et al. Direct binding of retromer to human papillomavirus type 16 minor capsid protein $L 2$ mediates endosome exit during viral infection. PLoS Pathog 2015;11:e1004699.
36. Lipovsky A, Popa A, Pimienta G, Wyler M, Bhan A et al. GenomeWide siRNA screen identifies the retromer as a cellular entry factor for human papillomavirus. Proc Natl Acad Sci U S A 2013:110:7452-7457

37. Zhang P, Monteiro da Silva G, Deatherage C, Burd C, DiMaio D. CellPenetrating Peptide Mediates Intracellular Membrane Passage of Human Papillomavirus L2 Protein to Trigger Retrograde Trafficking. Cell 2018;174:e13:1465-1476.

38. Pyeon D, Pearce SM, Lank SM, Ahlquist P, Lambert PF. Establishment of human papillomavirus infection requires cell cycle progression. PLoS Pathog 2009;5:e1000318.

39. Aydin I, Weber S, Snijder B, Samperio Ventayol P, Kuhbacher A et al. Large scale RNAi reveals the requirement of nuclear envelope breakdown for nuclear import of human papillomaviruses. PLoS Pathog 2014;10:e1004162.

40. Aydin I, Villalonga-Planells R, Greune L, Bronnimann MP, Calton CM et al. A central region in the minor capsid protein of papillomaviruses facilitates viral genome tethering and membrane penetration for mitotic nuclear entry. PLoS Pathog 2017;13:e1006308.

41. Bergvall M, Melendy T, Archambault J. The E1 proteins. Virology 2013:445:35-56.

42. McBride AA. The papillomavirus E2 proteins. Virology 2013:445:57-79.

43. Romanczuk H, Thierry F, Howley PM. Mutational analysis of cis elements involved in E2 modulation of human papillomavirus type 16 p97 and type 18 p105 promoters. J Virol 1990;64:2849-2859.

44. Wang HK, Duffy AA, Broker TR, Chow LT. Robust production and passaging of infectious HPV in squamous epithelium of primary human keratinocytes. Genes Dev 2009:23:181-194.

45. Banerjee NS, Wang HK, Broker TR, Chow LT. Human papillomavirus (HPV) E7 induces prolonged G2 following $\mathrm{S}$ phase reentry in differentiated human keratinocytes. J Biol Chem 2011;286:15473-15482.

46. Cerqueira C, Schiller JT. Papillomavirus assembly: an overview and perspectives. Virus Res 2017;231:103-107.

47. Jeon S, Allen-Hoffmann BL, Lambert PF. Integration of human papillomavirus type 16 into the human genome correlates with a selective growth advantage of cells. J Virol 1995;69:2989-2997.

48. McBride AA, Warburton A. The role of integration in oncogenic progression of HPV-associated cancers. PLoS Pathog 2017;13:e1006211.

49. Cancer Genome Atlas Network. Comprehensive genomic characterization of head and neck squamous cell carcinomas. Nature 2015;517:576-582.

50. Cancer Genome Atlas Research Network, Albert Einstein College of Medicine, Analytical Biological Services, Barretos Cancer Hospital, Baylor College of Medicine et al. Integrated genomic and molecular characterization of cervical cancer. Nature 2017:543:378-384.

51. Leung TW, Liu SS, Leung RC, Chu MM, Cheung AN et al. Hpv 16 E2 binding sites 1 and 2 become more methylated than E2 binding site 4 during cervical carcinogenesis. J Med Virol 2015;87:1022-1033.

52. Jeon S, Lambert PF. Integration of human papillomavirus type 16 DNA into the human genome leads to increased stability of E6 and E7 mRNAs: implications for cervical carcinogenesis. Proc Natl Acad Sci U S A 1995;92:1654-1658

53. Müller M, Prescott EL, Wasson CW, Macdonald A. Human papillomavirus E5 oncoprotein: function and potential target for antiviral therapeutics. Future Virol 2015;10:27-39.

54. Conrad M, Bubb VJ, Schlegel R. The human papillomavirus type 6 and 16 E5 proteins are membrane-associated proteins which associate with the 16-kilodalton pore-forming protein. J Virol 1993;67:6170-6178.

55. Gieswein CE, Sharom FJ, Wildeman AG. Oligomerization of the E5 protein of human papillomavirus type 16 occurs through multiple hydrophobic regions. Virology 2003;313:415-426. 
56. Wasson CW, Morgan EL, Muller M, Ross RL, Hartley M et al. Human papillomavirus type 18 E5 oncogene supports cell cycle progression and impairs epithelial differentiation by modulating growth factor receptor signalling during the virus life cycle. Oncotarget 2017;8:103581-103600.

57. Genther SM, Sterling S, Duensing S, Munger K, Sattler $\mathrm{C}$ et al. Quantitative role of the human papillomavirus type 16 E5 gene during the productive stage of the viral life cycle. J Virol 2003;77:2832-2842.

58. Fehrmann F, Klumpp DJ, Laimins LA. Human papillomavirus type 31 E5 protein supports cell cycle progression and activates late viral functions upon epithelial differentiation. J Virol 2003;77:2819-2831.

59. Leptak C, Ramon y Cajal S, Kulke R, Riese DJ, Riese DJ et al. Tumorigenic transformation of murine keratinocytes by the E5 genes of bovine papillomavirus type 1 and human papillomavirus type 16. J Virol 1991;65:7078-7083.

60. Goldstein DJ, Andresson T, Sparkowski JJ, Schlegel R. The BPV-1 E5 protein, the $16 \mathrm{kDa}$ membrane pore-forming protein and the PDGF receptor exist in a complex that is dependent on hydrophobic transmembrane interactions. Embo J 1992;11:4851-4859.

61. Riese DJ, DiMaio D. An intact PDGF signaling pathway is required for efficient growth transformation of mouse $\mathrm{C} 127$ cells by the bovine papillomavirus E5 protein. Oncogene 1995;10:1431-1439.

62. Karabadzhak AG, Petti LM, Barrera FN, Edwards APB, MoyaRodriguez $\mathrm{A}$ et al. Two transmembrane dimers of the bovine papillomavirus E5 oncoprotein clamp the PDGF $\beta$ receptor in an active dimeric conformation. Proc Natl Acad Sci U S A 2017:114:E7262-E7271

63. DiMaio D, Petti LM. The E5 proteins. Virology 2013:445:99-114.

64. Maufort JP, Williams SM, Pitot HC, Lambert PF. Human papillomavirus 16 E5 oncogene contributes to two stages of skin carcinogenesis. Cancer Res 2007;67:6106-6112.

65. Bouvard V, Matlashewski G, Gu ZM, Storey A, Banks L. The human papillomavirus type 16 E5 gene cooperates with the E7 gene to stimulate proliferation of primary cells and increases viral gene expression. Virology 1994:203:73-80.

66. Valle GF, Banks L. The human papillomavirus (HPV)-6 and HPV-16 E5 proteins co-operate with HPV-16 E7 in the transformation of primary rodent cells. J Gen Virol 1995;76 (Pt 5:1239-1245.

67. Maufort JP, Shai A, Pitot HC, Lambert PF. A role for HPV16 E5 in cervical carcinogenesis. Cancer Res 2010;70:2924-2931.

68. Chen SL, Lin ST, Tsai TC, Hsiao WC, Tsao Y-P, ErbB TYP. ErbB4 (JM-b/CYT-1)-induced expression and phosphorylation of c-Jun is abrogated by human papillomavirus type 16 E5 protein. Oncogene 2007;26:42-53.

69. Genther Williams SM, Disbrow GL, Schlegel R, Lee D, Threadgill DW et al. Requirement of epidermal growth factor receptor for hyperplasia induced by E5, a high-risk human papillomavirus oncogene. Cancer Res 2005;65:6534-6542.

70. Scott ML, Coleman DT, Kelly KC, Carroll JL, Woodby B et al. Human papillomavirus type 16 E5-mediated upregulation of Met in human keratinocytes. Virology 2018:519:1-11.

71. Straight SW, Herman B, McCance DJ. The E5 oncoprotein of human papillomavirus type 16 inhibits the acidification of endosomes in human keratinocytes. J Virol 1995;69:3185-3192.

72. Rodríguez MI, Finbow ME, Alonso A. Binding of human papillomavirus $16 \mathrm{E} 5$ to the $16 \mathrm{kDa}$ subunit $\mathrm{C}$ (proteolipid) of the vacuolar $\mathrm{H}+-$ ATPase can be dissociated from the E5-mediated epidermal growth factor receptor overactivation. Oncogene 2000;19:3727-3732.

73. Suprynowicz FA, Krawczyk E, Hebert JD, Sudarshan SR, Simic V et al. The human papillomavirus type 16 E5 oncoprotein inhibits epidermal growth factor trafficking independently of endosome acidification. J Virol 2010;84:10619-10629.

74. Hwang ES, Nottoli T, Dimaio D. The HPV16 E5 protein: expression, detection, and stable complex formation with transmembrane proteins in COS cells. Virology 1995;211:227-233.
75. Zhang B, Srirangam A, Potter DA, Roman A. Hpv16 E5 protein disrupts the c-Cbl-EGFR interaction and EGFR ubiquitination in human foreskin keratinocytes. Oncogene 2005;24:2585-2588.

76. Wetherill LF, Holmes KK, Verow M, Müller M, Howell G et al. HighRisk human papillomavirus E5 oncoprotein displays channelforming activity sensitive to small-molecule inhibitors. J Virol 2012:86:5341-5351.

77. Royle J, Dobson SJ, Müller M, Macdonald A. Emerging roles of viroporins encoded by DNA viruses: novel targets for antivirals? Viruses 2015;7:5375-5387.

78. Wetherill LF, Wasson CW, Swinscoe G, Kealy D, Foster R et al. Alkyl-imino sugars inhibit the pro-oncogenic ion channel function of human papillomavirus (HPV) E5. Antiviral Res 2018;158:113-121.

79. Belleudi F, Leone L, Purpura V, Cannella F, Scrofani $C$ et al. Hpv16 E5 affects the KGFR/FGFR2b-mediated epithelial growth through alteration of the receptor expression, signaling and endocytic traffic. Oncogene 2011;30:4963-4976.

80. Ranieri D, Belleudi F, Magenta A, Torrisi MR. Hpv16 E5 expression induces switching from FGFR2b to FGFR2c and epithelialmesenchymal transition. Int J Cancer 2015;137:61-72.

81. Chen SL, Huang CH, Tsai TC, Lu KY, Tsao YP. The regulation mechanism of $\mathrm{c}$-Jun and junB by human papillomavirus type 16 E5 oncoprotein. Arch Virol 1996;141:791-800.

82. Crusius K, Auvinen E, Alonso A. Enhancement of EGF- and PMAmediated MAP kinase activation in cells expressing the human papillomavirus type 16 E5 protein. Oncogene 1997;15:1437-1444.

83. Tsao YP, Li LY, Tsai TC, Chen SL. Human papillomavirus type 11 and 16 E5 represses p21(Wafl/Sdil/Cipl) gene expression in fibroblasts and keratinocytes. J Virol 1996;70:7535-7539.

84. Pedroza-Saavedra A, Lam EW, Esquivel-Guadarrama $F$ Gutierrez-Xicotencatl L. The human papillomavirus type 16 E5 oncoprotein synergizes with EGF-receptor signaling to enhance cell cycle progression and the down-regulation of p27(Kip1). Virology 2010;400:44-52.

85. Oh J-M, Kim S-H, Cho E-A, Song Y-S, Kim W-H et al. Human papillomavirus type 16 E5 protein inhibits hydrogen-peroxide-induced apoptosis by stimulating ubiquitin-proteasome-mediated degradation of Bax in human cervical cancer cells. Carcinogenesis 2010;31:402-410.

86. Kabsch K, Mossadegh N, Kohl A, Komposch G, Schenkel J et al. The HPV-16 E5 protein inhibits TRAIL- and FasL-mediated apoptosis in human keratinocyte raft cultures. Intervirology 2004:47:48-56.

87. Zhang B, Spandau DF, Roman A. E5 protein of human papillomavirus type 16 protects human foreskin keratinocytes from UV B-irradiation-induced apoptosis. J Virol 2002;76:220-231.

88. Gruener M, Bravo IG, Momburg F, Alonso A, Tomakidi P. The E5 protein of the human papillomavirus type 16 down-regulates HLA-I surface expression in calnexin-expressing but not in calnexin-deficient cells. Virol J 2007;4:116.

89. Ashrafi GH, Haghshenas MR, Marchetti B, O'Brien PM, Campo MS E5 protein of human papillomavirus type 16 selectively downregulates surface HLA class I. Int J Cancer 2005;113:276-283.

90. Campo MS, Graham SV, Cortese MS, Ashrafi GH, Araibi EH et al. Hpv-16 E5 down-regulates expression of surface HLA class I and reduces recognition by CD8 T cells. Virology 2010;407:137-142.

91. Zhang B, Li P, Wang E, Brahmi Z, Dunn KW et al. The E5 protein of human papillomavirus type 16 perturbs MHC class II antigen maturation in human foreskin keratinocytes treated with interferon-gamma. Virology 2003:310:100-108.

92. Miura S, Kawana K, Schust DJ, Fujii T, Yokoyama T et al. Cd1D, a sentinel molecule bridging innate and adaptive immunity, is downregulated by the human papillomavirus (HPV) E5 protein: a possible mechanism for immune evasion by HPV. J Virol 2010;84:11614-11623.

93. Cortese MS, Ashrafi GH, Campo MS. All 4 di-leucine motifs in the first hydrophobic domain of the $E 5$ oncoprotein of human 
papillomavirus type 16 are essential for surface MHC class I downregulation activity and E5 endomembrane localization. Int J Cancer 2010;126:1675-1682.

94. Ashrafi GH, Haghshenas M, Marchetti B, Campo MS. E5 protein of human papillomavirus 16 downregulates HLA class I and interacts with the heavy chain via its first hydrophobic domain. Int J Cancer 2006:119:2105-2112.

95. Kotnik Halavaty K, Regan J, Mehta K, Laimins L. Human papillomavirus E5 oncoproteins bind the A4 endoplasmic reticulum protein to regulate proliferative ability upon differentiation. Virology 2014;452-453:223-230.

96. Regan JA, Laimins LA. Bap31 is a novel target of the human papillomavirus E5 protein. J Virol 2008;82:10042-10051.

97. Scott ML, Woodby BL, Ulicny J, Raikhy G, Orr AW et al. Human papillomavirus 16 E5 inhibits interferon signaling and supports episomal viral maintenance. J Virol 2020;94 [Epub ahead of print 0601 2020].

98. Miyauchi S, Sanders PD, Guram K, Kim SS, Paolini F et al. Hpv16 E5 mediates resistance to PD-L1 blockade and can be targeted with rimantadine in head and neck cancer. Cancer Res 2020;80:732-746.

99. Schwarz E, Freese UK, Gissmann L, Mayer W, Roggenbuck B et al. Structure and transcription of human papillomavirus sequences in cervical carcinoma cells. Nature 1985;314:111-114.

100. Band V, De Caprio JA, Delmolino L, Kulesa V, Sager R. Loss of p53 protein in human papillomavirus type 16 E6-immortalized human mammary epithelial cells. J Virol 1991;65:6671-6676.

101. Liu Z, Ghai J, Ostrow RS, McGlennen RC, Faras AJ. The E6 gene of human papillomavirus type 16 is sufficient for transformation of baby rat kidney cells in cotransfection with activated Ha-ras. Virology 1994:201:388-396.

102. Halbert CL, Demers GW, Galloway DA. The E7 gene of human papillomavirus type 16 is sufficient for immortalization of human epithelial cells. J Virol 1991;65:473-478.

103. Song S, Liem A, Miller JA, Lambert PF. Human papillomavirus types 16 E6 and E7 contribute differently to carcinogenesis. Virology 2000;267:141-150.

104. Münger K, Phelps WC, Bubb V, Howley PM, Schlegel R. The E6 and E7 genes of the human papillomavirus type 16 together are necessary and sufficient for transformation of primary human keratinocytes. J Virol 1989;63:4417-4421.

105. Howie HL, Katzenellenbogen RA, Galloway DA. Papillomavirus E6 proteins. Virology 2009;384:324-334.

106. Nominé Y, Masson M, Charbonnier S, Zanier K, Ristriani T et al. Structural and functional analysis of E6 oncoprotein: insights in the molecular pathways of human papillomavirus-mediated pathogenesis. Mol Cell 2006;21:665-678.

107. Zanier K ould. M'hamed ould Sidi a, Boulade-Ladame C, Rybin V. Chappelle a, Atkinson a, Kieffer B, Trave G. solution structure analysis of the HPV16 E6 oncoprotein reveals a self-association mechanism required for E6-mediated degradation of p53. Structure 2012;20:604-617.

108. Ganti K, Broniarczyk J, Manoubi W, Massimi P, Mittal S et al. The human papillomavirus E6 PDZ binding motif: from life cycle to malignancy. Viruses 2015;7:3530-3551.

109. Scheffner M, Werness BA, Huibregtse JM, Levine AJ, Howley PM. The E6 oncoprotein encoded by human papillomavirus types 16 and 18 promotes the degradation of p53. Cell 1990;63:1129-1136.

110. Bieging KT, Mello SS, Attardi LD. Unravelling mechanisms of p53mediated tumour suppression. Nat Rev Cancer 2014;14:359-370.

111. Patel D, Huang SM, Baglia LA, McCance DJ. The E6 protein of human papillomavirus type 16 binds to and inhibits co-activation by CBP and p300. Embo J 1999;18:5061-5072.

112. Zimmermann H, Degenkolbe R, Bernard HU, O'Connor MJ. The human papillomavirus type 16 E6 oncoprotein can downregulate $\mathrm{p} 53$ activity by targeting the transcriptional coactivator CBP/p300. J Virol 1999;73:6209-6219.
113. Kumar A, Zhao Y, Meng G, Zeng M, Srinivasan S et al. Human papillomavirus oncoprotein E6 inactivates the transcriptional coactivator human ADA3. Mol Cell Biol 2002;22:5801-5812.

114. Lechner MS, Laimins LA. Inhibition of p53 DNA binding by human papillomavirus E6 proteins. J Virol 1994;68:4262-4273.

115. Thomas M, Banks L. Inhibition of Bak-induced apoptosis by HPV-18 E6. Oncogene 1998;17:2943-2954.

116. Thomas M, Banks L. Human papillomavirus (HPV) E6 interactions with Bak are conserved amongst E6 proteins from high and low risk HPV types. J Gen Virol 1999:80 (Pt 6:1513-1517.

117. Filippova M, Parkhurst L, Duerksen-Hughes PJ. The human papillomavirus 16 E6 protein binds to Fas-associated death domain and protects cells from Fas-triggered apoptosis. J Biol Chem 2004:279:25729-25744.

118. Garnett TO, Filippova M, Duerksen-Hughes PJ. Accelerated degradation of FADD and procaspase 8 in cells expressing human papilloma virus 16 E6 impairs TRAIL-mediated apoptosis. Cell Death Differ 2006;13:1915-1926.

119. Filippova M, Song H, Connolly JL, Dermody TS, DuerksenHughes PJ. The human papillomavirus $16 \mathrm{E} 6$ protein binds to tumor necrosis factor (TNF) R1 and protects cells from TNFinduced apoptosis. J Biol Chem 2002;277:21730-21739.

120. Vande Pol SB, Klingelhutz AJ. Papillomavirus E6 oncoproteins. Virology 2013;445:115-137.

121. Liu Y, Chen JJ, Gao Q, Dalal S, Hong Y et al. Multiple functions of human papillomavirus type 16 E6 contribute to the immortalization of mammary epithelial cells. J Virol 1999;73:7297-7307.

122. Nguyen ML, Nguyen MM, Lee D, Griep AE, Lambert PF. The PDZ ligand domain of the human papillomavirus type $16 \mathrm{E} 6$ protein is required for E6's induction of epithelial hyperplasia in vivo. $J$ Virol 2003;77:6957-6964.

123. Gardiol D, Kühne C, Glaunsinger B, Lee SS, Javier R et al. Oncogenic human papillomavirus E6 proteins target the discs large tumour suppressor for proteasome-mediated degradation. Oncogene 1999:18:5487-5496.

124. Nakagawa S, Huibregtse JM. Human scribble (Vartul) is targeted for ubiquitin-mediated degradation by the high-risk papillomavirus E6 proteins and the E6AP ubiquitin-protein ligase. Mol Cell Biol 2000;20:8244-8253.

125. Glaunsinger BA, Lee SS, Thomas M, Banks L, Javier R. Interactions of the PDZ-protein MAGI-1 with adenovirus E4-ORF1 and high-risk papillomavirus E6 oncoproteins. Oncogene 2000;19:5270-5280.

126. Thomas M, Laura R, Hepner K, Guccione E, Sawyers C et al. Oncogenic human papillomavirus E6 proteins target the MAGI-2 and MAGI-3 proteins for degradation. Oncogene 2002;21:5088-5096.

127. Kiyono T, Hiraiwa A, Fujita M, Hayashi Y, Akiyama T et al. Binding of high-risk human papillomavirus E6 oncoproteins to the human homologue of the Drosophila discs large tumor suppressor protein. Proc Natl Acad Sci U S A 1997;94:11612-11616.

128. Lee SS, Weiss RS, Javier RT. Binding of human virus oncoproteins to hDlg/SAP97, a mammalian homolog of the Drosophila discs large tumor suppressor protein. Proc Natl Acad Sci U S A 1997:94:6670-6675.

129. Ganti K, Massimi P, Manzo-Merino J, Tomaić V, Pim D et al. Interaction of the human papillomavirus E6 oncoprotein with sorting nexin 27 modulates endocytic cargo transport pathways. PLoS Pathog 2016;12:e1005854.

130. Morgan EL, Scarth JA, Patterson MR, Wasson CW, Hemingway GC etal.E6-Mediated activation of JNK drives EGFR signalling to promote proliferation and viral oncoprotein expression in cervical cancer. Cell Death Differ 2020 [Epub ahead of print 10 Dec 2020].

131. Banks L, Pim D, Thomas M. Human tumour viruses and the deregulation of cell polarity in cancer. Nat Rev Cancer 2012;12:877-886.

132. Thomas M, Myers MP, Massimi P, Guarnaccia C, Banks L. Analysis of multiple HPV E6 PDZ interactions defines type-specific 
PDZ fingerprints that predict oncogenic potential. PLOS Pathog 2016:12:e1005766.

133. Boon SS, Banks L. High-Risk human papillomavirus E6 oncoproteins interact with 14-3-3 $\zeta$ in a PDZ binding motif-dependent manner. J Virol 2013:87:1586-1595.

134. Katzenellenbogen R. Telomerase induction in HPV infection and oncogenesis. Viruses 2017;9:180

135. Klingelhutz AJ, Foster SA, McDougall JK. Telomerase activation by the E6 gene product of human papillomavirus type 16. Nature 1996:380:79-82.

136. Veldman T, Horikawa I, Barrett JC, Schlegel R. Transcriptional activation of the telomerase hTERT gene by human papillomavirus type 16 E6 oncoprotein. J Virol 2001;75:4467-4472.

137. Van Doorslaer K, Burk RD. Association between hTERT activation by HPV E6 proteins and oncogenic risk. Virology 2012;433:216-219.

138. Zhan T, Rindtorff N, Boutros M. Wnt signaling in cancer. Oncogene 2017:36:1461-1473.

139. Bonilla-Delgado J, Bulut G, Liu X, Cortés-Malagón EM, Schlegel R et al. The E6 oncoprotein from HPV16 enhances the canonical Wnt/ $\beta$-catenin pathway in skin epidermis in vivo. Mol Cancer Res 2012;10:250-258

140. Sominsky S, Kuslansky $Y$, Shapiro B, Jackman A, Haupt $Y$ et al. Hpv16 E6 and E6AP differentially cooperate to stimulate or augment Wnt signaling. Virology 2014:468-470:510-523.

141. Drews CM, Case S, Vande Pol SB. E6 proteins from high-risk HPV, low-risk HPV, and animal papillomaviruses activate the Wnt/ $\beta$-catenin pathway through E6AP-dependent degradation of NHERF1. PLoS Pathog 2019;15:e1007575.

142. Chen PM, Cheng YW, Wang YC, Wu T-C, Chen C-Y et al. Up-Regulation of FoxM1 by E6 oncoprotein through the MZF1/ NKX2-1 axis is required for human papillomavirus-associated tumorigenesis. Neoplasia 2014;16:961-971.

143. Rampias T, Boutati E, Pectasides E, Sasaki C, Kountourakis P et al. Activation of Wnt signaling pathway by human papillomavirus E6 and E7 oncogenes in HPV16-positive oropharyngeal squamous carcinoma cells. Mol Cancer Res 2010;8:433-443.

144. Bray SJ. Notch signalling in context. Nat Rev Mol Cell Biol 2016;17:722-735

145. Ntziachristos P, Lim JS, Sage J, Aifantis I. From fly wings to targeted cancer therapies: a centennial for Notch signaling. Cancer Cell 2014:25:318-334.

146. Zagouras P, Stifani S, Blaumueller CM, Carcangiu ML, ArtavanisTsakonas S. Alterations in Notch signaling in neoplastic lesions of the human cervix. Proc Natl Acad Sci U S A 1995:92:6414-6418.

147. Vliet-Gregg PA, Hamilton JR, Katzenellenbogen RA. NFX1-123 and human papillomavirus 16E6 increase Notch expression in keratinocytes. J Virol 2013;87:13741-13750

148. Sun W, Gaykalova DA, Ochs MF, Mambo E, Arnaoutakis D et al. Activation of the Notch pathway in head and neck cancer. Cancer Res 2014:74:1091-1104.

149. Talora C, Sgroi DC, Crum CP, Dotto GP. Specific down-modulation of Notch1 signaling in cervical cancer cells is required for sustained HPV-E6/E7 expression and late steps of malignant transformation. Genes Dev 2002;16:2252-2263.

150. Porta C, Paglino C, Mosca A. Targeting PI3K/Akt/mTOR signaling in cancer. Front Oncol 2014:4:64.

151. Contreras-Paredes A, De la Cruz-Hernández E, MartínezRamírez I, Dueñas-González A, Lizano M. E6 variants of human papillomavirus 18 differentially modulate the protein kinase B/ phosphatidylinositol 3-kinase (akt/PI3K) signaling pathway. Virology 2009:383:78-85.

152. Adey NB, Huang L, Ormonde PA, Baumgard ML, Pero R et al. Threonine phosphorylation of the MMAC1/PTEN PDZ binding domain both inhibits and stimulates PDZ binding. Cancer Res 2000;60:35-37.
153. Takahashi Y, Morales FC, Kreimann EL, Georgescu MM. Pten tumor suppressor associates with NHERF proteins to attenuate PDGF receptor signaling. Embo J 2006;25:910-920.

154. Accardi R, Rubino R, Scalise M, Gheit T, Shahzad N et al. E6 and E7 from human papillomavirus type 16 cooperate to target the PDZ protein $\mathrm{Na} / \mathrm{H}$ exchange regulatory factor 1. J Virol 2011:85:8208-8216.

155. Lu Z, Hu X, Li Y, Zheng L, Zhou Y et al. Human papillomavirus 16 E6 oncoprotein interferences with insulin signaling pathway by binding to tuberin. J Biol Chem 2004;279:35664-35670.

156. Zheng L, Ding H, Lu Z, Li Y, Pan Y et al. E3 ubiquitin ligase E6APmediated TSC2 turnover in the presence and absence of HPV16 E6. Genes Cells 2008;13:285-294.

157. Spangle JM, Münger $\mathrm{K}$. The human papillomavirus type 16 E6 oncoprotein activates mTORC1 signaling and increases protein synthesis. J Virol 2010;84:9398-9407.

158. Spangle JM, Munger K. The HPV16 E6 oncoprotein causes prolonged receptor protein tyrosine kinase signaling and enhances internalization of phosphorylated receptor species. PLoS Pathog 2013;9:e1003237

159. Moroishi T, Hansen CG, Guan KL. The emerging roles of YAP and TAZ in cancer. Nat Rev Cancer 2015;15:73-79.

160. Webb Strickland S, Brimer N, Lyons C, Vande Pol SB. Human papillomavirus E6 interaction with cellular PDZ domain proteins modulates YAP nuclear localization. Virology 2018:516:127-138.

161. He C, Lv X, Huang C, Angeletti PC, Hua G et al. A human Papillomavirus-Independent cervical cancer animal model reveals unconventional mechanisms of cervical carcinogenesis. Cell Rep 2019;26:2636-2650.

162. Morgan EL, Patterson MR, Ryder EL, Lee SY, Wasson CW et al. MicroRNA-18a targeting of the STK4/MST1 tumour suppressor is necessary for transformation in HPV positive cervical cancer. PLoS Pathog 2020;16:e1008624.

163. Thomas SJ, Snowden JA, Zeidler MP, Danson SJ. The role of JAK/STAT signalling in the pathogenesis, prognosis and treatment of solid tumours. Br J Cancer 2015;113:365-371.

164. Morgan EL, Macdonald A. Manipulation of JAK/STAT signalling by high-risk HPVs: potential therapeutic targets for HPV-associated malignancies. Viruses 2020;12:977

165. Morgan EL, Macdonald A. Jak2 inhibition impairs proliferation and sensitises cervical cancer cells to cisplatin-induced cell death. Cancers 2019:11:1934

166. Ronco LV, Karpova AY, Vidal M, Howley PM. Human papillomavirus 16 E6 oncoprotein binds to interferon regulatory factor-3 and inhibits its transcriptional activity. Genes Dev 1998;12:2061-2072.

167. Li S, Labrecque S, Gauzzi MC, Cuddihy AR, Wong AH et al. The human papilloma virus (HPV)-18 E6 oncoprotein physically associates with Tyk2 and impairs Jak-STAT activation by interferonalpha. Oncogene 1999;18:5727-5737.

168. Chiang C, Pauli EK, Biryukov J, Feister KF, Meng M et al. The human papillomavirus E6 oncoprotein targets USP15 and TRIM25 to suppress RIG-I-mediated innate immune signaling. $J$ Virol 2018;92 [Epub ahead of print 1503 2018]

169. Reiser J, Hurst J, Voges M, Krauss P, Münch P et al. High-Risk human papillomaviruses repress constitutive kappa interferon transcription via E6 to prevent pathogen recognition receptor and antiviral-gene expression. J Virol 2011;85:11372-11380.

170. Zhao S. Specific type epigenetic changes in cervical cancers. In: Verma M (editor). Methods in Molecular Biology (Methods and Protocols), Cancer Epigenetics. New York, NY: 1238: Humana Press; 2015. pp. 733-749.

171. Leonard SM, Wei W, Collins SI, Pereira M, Diyaf A et al. Oncogenic human papillomavirus imposes an instructive pattern of DNA methylation changes which parallel the natural history of cervical HPV infection in young women. Carcinogenesis 2012:33:1286-1293. 
172. Au Yeung CL, Tsang WP, Tsang TY, Co NN, Yau PL et al. Hpv-16 E6 upregulation of DNMT1 through repression of tumor suppressor p53. Oncol Rep 2010;24:1599-1604.

173. Lin RK, Wu C-Y, Chang J-W, Juan L-J, Hsu H-S et al. Dysregulation of $\mathrm{p} 53 / \mathrm{Sp} 1$ control leads to DNA methyltransferase-1 overexpression in lung cancer. Cancer Res 2010;70:5807-5817.

174. Yanatatsaneejit $P$, Chalertpet K, Sukbhattee J, Nuchcharoen I, Phumcharoen $\mathrm{P}$ et al. Promoter methylation of tumor suppressor genes induced by human papillomavirus in cervical cancer. Oncol Lett 2020;20:955-961.

175. Hsu CH, Peng KL, Jhang HC, Lin CH, Wu S-Y. The HPV E6 oncoprotein targets histone methyltransferases for modulating specific gene transcription. Oncogene 2012;31:2335-2349.

176. Tornesello ML, Faraonio R, Buonaguro L, Annunziata C, Starita N et al. The role of microRNAs, long non-coding RNAs, and circular RNAs in cervical cancer. Front Oncol 2020;10:150.

177. Gebert LFR, MacRae IJ. Regulation of microRNA function in animals. Nat Rev Mol Cell Biol 2019;20:21-37.

178. Wang X, Wang HK, McCoy JP, Banerjee NS, Rader JS etal. Oncogenic HPV infection interrupts the expression of tumor-suppressive miR-34a through viral oncoprotein E6. RNA 2009;15:637-647.

179. MartinezI,GardinerAS,BoardKF,MonzonFA,Edwards RPetal. Human papillomavirus type 16 reduces the expression of microRNA-218 in cervical carcinoma cells. Oncogene 2008;27:2575-2582.

180. Cheng Y, Geng L, Zhao L, Zuo P, Wang J. Human papillomavirus E6-regulated microRNA-20b promotes invasion in cervical cancer by targeting tissue inhibitor of metalloproteinase 2. Mol Med Rep 2017;16:5464-5470

181. Liu X. Up-Regulation of miR-20a by HPV16 E6 exerts growthpromoting effects by targeting PDCD6 in cervical carcinoma cells. Biomed Pharmacother 2018;102:996-1002.

182. Marchese FP, Raimondi I, Huarte M. The multidimensional mechanisms of long noncoding RNA function. Genome Biol 2017;18:206.

183. Yang M, Zhai X, Xia B, Wang Y, Lou G. Long noncoding RNA CCHE1 promotes cervical cancer cell proliferation via upregulating PCNA. Tumour Biol 2015;36:7615-7622.

184. Sharma S, Munger K. Expression of the cervical carcinoma expressed PCNA regulatory (CCEPR) long noncoding RNA is driven by the human papillomavirus E6 protein and modulates cell proliferation independent of PCNA. Virology 2018;518:8-13.

185. Barr JA, Hayes KE, Brownmiller T, Harold AD, Jagannathan $R$ et al. Long non-coding RNA FAM83H-AS1 is regulated by human papillomavirus 16 E6 independently of p53 in cervical cancer cells. Sci Rep 2019:9:3662.

186. McLaughlin-Drubin ME, Münger K. The human papillomavirus E7 oncoprotein. Virology 2009;384:335-344.

187. Jabbar SF, Park S, Schweizer J, Berard-Bergery M, Pitot HC et al. Cervical cancers require the continuous expression of the human papillomavirus type 16 E7 oncoprotein even in the presence of the viral E6 oncoprotein. Cancer Res 2012;72:4008-4016.

188. Mirabello L, Yeager M, Yu K, Clifford GM, Xiao Y et al. Hpv16 E7 genetic conservation is critical to carcinogenesis. Cell 2017:170:1164-1174

189. Phelps WC, Yee CL, Münger K, Howley PM. The human papillomavirus type 16 E7 gene encodes transactivation and transformation functions similar to those of adenovirus E1A. Cell 1988;53:539-547.

190. Barbosa MS, Edmonds C, Fisher C, Schiller JT, Lowy DR et al. The region of the HPV E7 oncoprotein homologous to adenovirus E1A and SV40 large T antigen contains separate domains for $\mathrm{Rb}$ binding and casein kinase $\mathrm{II}$ phosphorylation. Embo $J$ 1990;9:153-160.

191. Firzlaff JM, Galloway DA, Eisenman RN, Lüscher B. The E7 protein of human papillomavirus type 16 is phosphorylated by casein kinase II. New Biol 1989:1:44-53.
192. Knapp AA, McManus PM, Bockstall K, Moroianu J. Identification of the nuclear localization and export signals of high risk HPV16 E7 oncoprotein. Virology 2009:383:60-68

193. Chen HZ, Tsai SY, Leone G. Emerging roles of E2Fs in cancer: an exit from cell cycle control. Nat Rev Cancer 2009:9:785-797.

194. Todorovic B, Hung K, Massimi P, Avvakumov N, Dick FA et al. Conserved region 3 of human papillomavirus 16 E7 contributes to deregulation of the retinoblastoma tumor suppressor. J Virol 2012:86:13313-13323.

195. Nor Rashid N, Yusof R, Watson RJ. Disruption of repressive p130DREAM complexes by human papillomavirus 16 E6/E7 oncoproteins is required for cell-cycle progression in cervical cancer cells. J Gen Virol 2011;92:2620-2627.

196. Chien WM, Parker JN, Schmidt-Grimminger DC, Broker TR Chow LT. Casein kinase II phosphorylation of the human papillomavirus-18 E7 protein is critical for promoting S-phase entry. Cell Growth Differ 2000;11:425-435.

197. Genovese NJ, Banerjee NS, Broker TR, Chow LT. Casein kinase II motif-dependent phosphorylation of human papillomavirus E7 protein promotes p130 degradation and S-phase induction in differentiated human keratinocytes. J Virol 2008;82:4862-4873.

198. Huh K, Zhou X, Hayakawa H, Cho JY, Libermann TA et al. Human papillomavirus type 16 E7 oncoprotein associates with the cullin 2 ubiquitin ligase complex, which contributes to degradation of the retinoblastoma tumor suppressor. J Virol 2007;81:9737-9747.

199. White EA, Sowa ME, Tan MJ, Jeudy S, Hayes SD et al. Systematic identification of interactions between host cell proteins and E7 oncoproteins from diverse human papillomaviruses. Proc Natl Acad Sci U S A 2012;109:E260-E267.

200. Darnell GA, Schroder WA, Antalis TM, Lambley E, Major L et al. Human papillomavirus E7 requires the protease calpain to degrade the retinoblastoma protein. I Biol Chem 2007;282:37492-37500.

201. Tomita T, Huibregtse JM, Matouschek A. A masked initiation region in retinoblastoma protein regulates its proteasomal degradation. Nat Commun 2020;11:2019.

202. Zhang B, Chen W, Roman A. The E7 proteins of low- and highrisk human papillomaviruses share the ability to target the pRB family member p130 for degradation. Proc Natl Acad Sci U S A 2006:103:437-442.

203. Hwang SG, Lee D, Kim J, Seo T, Choe J. Human papillomavirus type $16 \mathrm{E} 7$ binds to E2F1 and activates E2F1-driven transcription in a retinoblastoma protein-independent manner. $J$ Biol Chem 2002;277:2923-2930.

204. Lyons TE, Salih M, Tuana BS. Activating E2Fs mediate transcriptional regulation of human E2F6 repressor. Am J Physiol Cell Physiol 2006:290:C189-C199.

205. Attwooll C, Oddi S, Cartwright $\mathrm{P}$, Prosperini E, Agger $\mathrm{K}$ et al. A novel repressive E2F6 complex containing the polycomb group protein, EPC1, that interacts with EZH2 in a proliferation-specific manner. J Biol Chem 2005;280:1199-1208.

206. McLaughlin-Drubin ME, Huh KW, Münger K. Human papillomavirus type 16 E7 oncoprotein associates with E2F6. J Virol 2008:82:8695-8705.

207. Nguyen CL, Münger K. Direct association of the HPV16 E7 oncoprotein with cyclin A/Cdk2 and cyclin E/CDK2 complexes. Virology 2008;380:21-25.

208. Zerfass K, Schulze A, Spitkovsky D, Friedman V, Henglein B et al. Sequential activation of cyclin $\mathrm{E}$ and cyclin a gene expression by human papillomavirus type 16 E7 through sequences necessary for transformation. J Virol 1995;69:6389-6399.

209. Zerfass-Thome K, Zwerschke W, Mannhardt B, Tindle R, Botz JW et al. Inactivation of the CDK inhibitor p27Kip1 by the human papillomavirus type 16 E7 oncoprotein. Oncogene 1996;13:2323-2330.

210. Funk JO, Waga S, Harry JB, Espling E, Stillman B et al. Inhibition of CDK activity and PCNA-dependent DNA replication by p21 is blocked by interaction with the HPV-16 E7 oncoprotein. Genes Dev 1997;11:2090-2100. 
211. Jones DL, Alani RM, Münger K. The human papillomavirus E7 oncoprotein can uncouple cellular differentiation and proliferation in human keratinocytes by abrogating p21Cip1-mediated inhibition of Cdk2. Genes Dev 1997:11:2101-2111.

212. White EA, Münger K, Howley PM. High-Risk human papillomavirus E7 proteins target PTPN14 for degradation. mBio 2016;7:e01530-16 [Epub ahead of print 2009 2016].

213. Szalmás A, Tomaić V, Basukala O, Massimi P, Mittal S et al. The PTPN14 tumor suppressor is a degradation target of human papillomavirus E7. J Virol 2017;91

214. Hatterschide J, Bohidar AE, Grace M, Nulton TJ, Kim HW et al. PTPN14 degradation by high-risk human papillomavirus E7 limits keratinocyte differentiation and contributes to HPV-mediated oncogenesis. Proc Natl Acad SciU S A 2019;116:7033-7042.

215. Yun HY, Kim MW, Lee HS, Kim W, Shin JH et al. Structural basis for recognition of the tumor suppressor protein PTPN14 by the oncoprotein E7 of human papillomavirus. PLoS Biol 2019;17:e3000367.

216. Pietenpol JA, Stein RW, Moran E, Yaciuk P, Schlegel R et al. TgfBeta 1 inhibition of c-myc transcription and growth in keratinocytes is abrogated by viral transforming proteins with pRB binding domains. Cell 1990;61:777-785.

217. Lee DK, Kim BC, Kim IY, Cho EA, Satterwhite DJ et al. The human papilloma virus E7 oncoprotein inhibits transforming growth factor-beta signaling by blocking binding of the Smad complex to its target sequence. J Biol Chem 2002;277:38557-38564.

218. James CD, Fontan CT, Otoa R, Das D, Prabhakar AT et al. Human papillomavirus 16 E6 and E7 synergistically repress innate immune gene transcription. mSphere 2020;5:e00828-19

219. Lau L, Gray EE, Brunette RL, Stetson DB. DNA tumor virus oncogenes antagonize the cGAS-STING DNA-sensing pathway. Science 2015;350:568-571.

220. Lo Cigno I, Calati F, Borgogna C, Zevini A, Albertini S et al. Human papillomavirus E7 oncoprotein subverts host innate immunity via SUV39H1-Mediated epigenetic silencing of immune sensor genes. J Virol 2020;94

221. Wu L, Cao J, Cai WL, Lang SM, Horton JR et al. KDM5 histone demethylases repress immune response via suppression of sting. PLoS Biol 2018;16:e2006134.

222. Hasan UA, Zannetti C, Parroche P, Goutagny N, Malfroy M et al. The human papillomavirus type 16 E7 oncoprotein induces a transcriptional repressor complex on the Toll-like receptor 9 promoter. J Exp Med 2013;210:1369-1387.

223. Richards KH, Wasson CW, Watherston O, Doble R, Eric Blair G et al. The human papillomavirus (HPV) E7 protein antagonises an imiquimod-induced inflammatory pathway in primary human keratinocytes. Sci Rep 2015;5:12922.

224. Richards KH, Doble R, Wasson CW, Haider M, Blair GE et al. Human papillomavirus E7 oncoprotein increases production of the anti-inflammatory interleukin-18 binding protein in keratinocytes. J Virol 2014:88:4173-4179.

225. Barnard P, McMillan NA. The human papillomavirus E7 oncoprotein abrogates signaling mediated by interferon-alpha. Virology 1999:259:305-313.

226. Park JS, Kim EJ, Kwon HJ, Hwang ES, Namkoong SE et al. Inactivation of interferon regulatory factor-1 tumor suppressor protein by HPV E7 oncoprotein. Implication for the E7-mediated immune evasion mechanism in cervical carcinogenesis. J Biol Chem 2000;275:6764-6769

227. Bergot AS, Ford N, Leggatt GR, Wells JW, Frazer IH et al. Hpv16-E7 expression in squamous epithelium creates a local immune suppressive environment via CCL2- and CCL5- mediated recruitment of mast cells. PLoS Pathog 2014;10:e1004466.

228. Cicchini L, Westrich JA, Xu T, Vermeer DW, Berger JN et al. Suppression of antitumor immune responses by human papillomavirus through epigenetic downregulation of Cxcl14. mBio 2016;7:e00270-16
229. Bottley G, Watherston OG, Hiew YL, Norrild B, Cook GP et al. HighRisk human papillomavirus E7 expression reduces cell-surface MHC class I molecules and increases susceptibility to natural killer cells. Oncogene 2008;27:1794-1799.

230. Korzeniewski N, Spardy N, Duensing A, Duensing S. Genomic instability and cancer: lessons learned from human papillomaviruses. Cancer Lett 2011;305:113-122.

231. Bester AC, Roniger M, Oren YS, Im MM, Sarni D et al. Nucleotide deficiency promotes genomic instability in early stages of cancer development. Cell 2011:145:435-446.

232. Mehta K, Laimins L. Human papillomaviruses preferentially recruit DNA repair factors to viral genomes for rapid repair and amplification. mBio 2018;9:e00064-18

233. Moody CA, Laimins LA. Human papillomaviruses activate the ATM DNA damage pathway for viral genome amplification upon differentiation. PLoS Pathog 2009;5:e1000605.

234. Hong $S$, Cheng S, lovane A, Laimins LA. Stat-5 regulates transcription of the topoisomerase $\| \beta$-Binding protein 1 (TopBP1) gene to activate the ATR pathway and promote human papillomavirus replication. mBio 2015;6:e02006-02015.

235. Blackford AN, Jackson SP. Atm, ATR, and DNA-PK: the Trinity at the heart of the DNA damage response. Mol Cell 2017;66:801-817.

236. Hong S, Laimins LA. The JAK-STAT transcriptional regulator, STAT-5, activates the ATM DNA damage pathway to induce HPV 31 genome amplification upon epithelial differentiation. PLOS Pathog 2013;9:e1003295

237. Hong S, Dutta A, Laimins LA. The acetyltransferase Tip60 is a critical regulator of the differentiation-dependent amplification of human papillomaviruses. J Virol 2015;89:4668-4675.

238. Gillespie KA, Mehta KP, Laimins LA, Moody CA. Human papillomaviruses recruit cellular DNA repair and homologous recombination factors to viral replication centers. J Virol 2012;86:9520-9526.

239. Duensing S, Lee LY, Duensing A, Basile J, Piboonniyom S et al. The human papillomavirus type 16 E6 and E7 oncoproteins cooperate to induce mitotic defects and genomic instability by uncoupling centrosome duplication from the cell division cycle. Proc Natl Acad Sci U S A 2000;97:10002-10007.

240. Duensing S, Münger K. The human papillomavirus type 16 E6 and E7 oncoproteins independently induce numerical and structural chromosome instability. Cancer Res 2002;62:7075-7082.

241. Nguyen CL, Eichwald C, Nibert ML, Münger K. Human papillomavirus type 16 E7 oncoprotein associates with the centrosomal component gamma-tubulin. J Virol 2007;81:13533-13543.

242. Paoli P, Giannoni E, Chiarugi P. Anoikis molecular pathways and its role in cancer progression. Biochim Biophys Acta 2013;1833:3481-3498.

243. DeMasi J, Huh KW, Nakatani Y, Münger K, Howley PM. Bovine papillomavirus E7 transformation function correlates with cellular p600 protein binding. Proc Natl Acad Sci U S A 2005;102:11486-11491.

244. DeMasi J, Chao MC, Kumar AS, Howley PM. Bovine papillomavirus E7 oncoprotein inhibits anoikis. J Virol 2007;81:9419-9425.

245. Huh KW, DeMasi J, Ogawa H, Nakatani Y, Howley PM et al. Association of the human papillomavirus type 16 E7 oncoprotein with the 600-kDa retinoblastoma protein-associated factor, p600. Proc Natl Acad Sci U S A 2005;102:11492-11497.

246. Burgers WA, Blanchon L, Pradhan S, de Launoit Y, Kouzarides T et al. Viral oncoproteins target the DNA methyltransferases. Oncogene 2007;26:1650-1655.

247. McLaughlin-Drubin ME, Crum CP, Münger K. Human papillomavirus E7 oncoprotein induces Kdmba and KDM6B histone demethylase expression and causes epigenetic reprogramming. Proc Natl Acad Sci U S A 2011;108:2130-2135.

248. Gameiro SF, Kolendowski B, Zhang A, Barrett JW, Nichols AC et al. Human papillomavirus dysregulates the cellular apparatus controlling the methylation status of H3K27 in different human 
cancers to consistently alter gene expression regardless of tissue of origin. Oncotarget 2017:8:72564-72576.

249. Soto DR, Barton C, Munger K, McLaughlin-Drubin ME. Kdm6A addiction of cervical carcinoma cell lines is triggered by E7 and mediated by p21Cip1 suppression of replication stress. PLoS Pathog 2017;13:e1006661.

250. Brehm A, Nielsen SJ, Miska EA, McCance DJ, Reid JL et al. The E7 oncoprotein associates with $\mathrm{Mi} 2$ and histone deacetylase activity to promote cell growth. Embo J 1999;18:2449-2458.

251. Longworth MS, Laimins LA. The binding of histone deacetylases and the integrity of zinc finger-like motifs of the E7 protein are essential for the life cycle of human papillomavirus type 31. J Virol 2004;78:3533-3541.

252. Longworth MS, Wilson R, Laimins LA. HPV31 E7 facilitates replication by activating E2F2 transcription through its interaction with HDACs. Embo J 2005;24:1821-1830.

253. Huang SM, McCance DJ. Down regulation of the interleukin-8 promoter by human papillomavirus type $16 \mathrm{E} 6$ and E7 through effects on CREB binding protein/p300 and P/CAF. J Virol 2002;76:8710-8721.

254. Avvakumov N, Torchia J, Mymryk JS. Interaction of the HPV E7 proteins with the pCAF acetyltransferase. Oncogene 2003;22:3833-3841.

255. Bernat A, Avvakumov N, Mymryk JS, Banks L. Interaction between the HPV E7 oncoprotein and the transcriptional coactivator p300. Oncogene 2003:22:7871-7881

256. Baldwin A, Huh KW, Münger K. Human papillomavirus E7 oncoprotein dysregulates steroid receptor coactivator 1 localization and function. J Virol 2006;80:6669-6677.

257. Yi R, Poy MN, Stoffel M, Fuchs E. A skin microRNA promotes differentiation by repressing 'stemness'. Nature 2008;452:225-229.

258. Melar-New M, Laimins LA. Human papillomaviruses modulate expression of microRNA 203 upon epithelial differentiation to control levels of p63 proteins. J Virol 2010;84:5212-5221.

259. Peta E, Sinigaglia A, Masi G, Di Camillo B, Grassi A et al. Hpv16 E6 and $\mathrm{E} 7$ upregulate the histone lysine demethylase KDM2B through the c-MYC/miR-146a-5p axys. Oncogene 2018;37:1654-1668.

260. Hong S, Cheng S, Songock W, Bodily J, Laimins LA. Suppression of microRNA 424 levels by human papillomaviruses is necessary for differentiation-dependent genome amplification. J Virol 2017:91

261. Li Q, Feng Y, Chao X, Shi S, Liang M et al. HOTAIR contributes to cell proliferation and metastasis of cervical cancer via targetting miR-23b/MAPK1 axis. Biosci Rep 2018;38

262. Sharma S, Mandal P, Sadhukhan T, Roy Chowdhury R, Ranjan Mondal $\mathrm{N}$ et al. Bridging links between long noncoding RNA HOTAIR and HPV oncoprotein E7 in cervical cancer pathogenesis. Sci Rep 2015;5:11724.

263. Sharma S, Munger $\mathrm{K}$. The role of long noncoding RNAs in human papillomavirus-associated pathogenesis. Pathogens 2020;9:289

264. lancu IV, Anton G, Botezatu A, Huica I, Nastase A, Socolov DG et al. LINC01101 and LINC00277 expression levels as novel factors in HPV-induced cervical neoplasia. J Cell Mol Med 2017;21:3787-3794.

265. He H, Liu X, Liu Y, Zhang M, Lai Y et al. Human papillomavirus E6/ E7 and long noncoding RNA TMPOP2 mutually upregulated gene expression in cervical cancer cells. J Virol 2019;93

266. Jiang Y, Li Y, Fang S, Jiang B, Qin C et al. The role of MALAT1 correlates with HPV in cervical cancer. Oncol Lett 2014;7:2135-2141.

267. Liang H, Zhang C, Guan H, Liu J, Cui Y. Lncrna DANCR promotes cervical cancer progression by upregulating ROCK1 via sponging miR-335-5p. J Cell Physiol 2019;234:7266-7278.

268. Hazawa M, Lin DC, Handral H, Xu L, Chen Y et al. ZNF750 is a lineage-specific tumour suppressor in squamous cell carcinoma. Oncogene 2017:36:2243-2254.

269. Harper KL, Mcdonnell E, Whitehouse A. Circrnas: from anonymity to novel regulators of gene expression in cancer (review). Int J Oncol 2019:55:1183-1193.
270. Zheng SR, Zhang HR, Zhang ZF, Lai SY, Huang LJ et al. Human papillomavirus 16 E7 oncoprotein alters the expression profiles of circular RNAs in CaSki cells. J Cancer 2018:9:3755-3764.

271. Wang H, Zhao Y, Chen M, Cui J. Identification of novel long noncoding and circular RNAs in human Papillomavirus-Mediated cervical cancer. Front Microbiol 2017;8:8.

272. Jiao J, Zhang T, Jiao X, Huang T, Zhao L et al. hsa_circ_0000745 promotes cervical cancer by increasing cell proliferation, migration, and invasion. J Cell Physiol 2020;235:1287-1295.

273. Liu J, Wang D, Long Z, Liu J, Li W. CircRNA8924 promotes cervical cancer cell proliferation, migration and invasion by competitively binding to MiR-518d-5p /519-5p family and modulating the expression of CBX8. Cell Physiol Biochem 2018:48:173-184.

274. Zhao J, Lee EE, Kim J, Yang R, Chamseddin B et al. Transforming activity of an oncoprotein-encoding circular RNA from human papillomavirus. Nat Commun 2019;10:2300.

275. Chen SL, Tsai TZ, Han CP, Tsao YP. Mutational analysis of human papillomavirus type $11 \mathrm{E} 5 \mathrm{a}$ oncoprotein. J Virol 1996;70:3502-3508.

276. Krawczyk E, Suprynowicz FA, Hebert JD, Kamonjoh CM, Schlegel R. The human papillomavirus type 16 E5 oncoprotein translocates calpactin I to the perinuclear region. J Virol 2011:85:10968-10975.

277. Lazarczyk M, Pons C, Mendoza J-A, Cassonnet P, Jacob Y et al. Regulation of cellular zinc balance as a potential mechanism of EVER-mediated protection against pathogenesis by cutaneous oncogenic human papillomaviruses. J Exp Med 2008;205:35-42.

278. Krawczyk E, Hanover JA, Schlegel R, Suprynowicz FA. Karyopherin beta3: a new cellular target for the HPV-16 E5 oncoprotein. Biochem Biophys Res Commun 2008:371:684-688.

279. Müller M, Wasson CW, Bhatia R, Boxall S, Millan D et al. YIP1 family member 4 (YIPF4) is a novel cellular binding partner of the papillomavirus E5 proteins. Sci Rep 2015;5:12523.

280. Shimada M, Yamashita A, Saito M, Ichino M, Kinjo T et al. The human papillomavirus E6 protein targets apoptosis-inducing factor (AIF) for degradation. Sci Rep 2020;10:14195.

281. Yim EK, Lee KH, Myeong J, Tong SY, Um S-J, et al. Novel interaction between HPV E6 and BARD1 (BRCA1-associated ring domain 1) and its biologic roles. DNA Cell Biol 2007;26:753-761.

282. Wang F, Wang J, Wang J, Zhang L, Fu $\mathrm{H}$ et al. BCCIP $\beta$ facilitates p53 ubiquitination via binding with E6 protein in high-risk HPV positive head and neck squamous cell carcinoma. Biochem Biophys Res Commun 2020;529:685-691.

283. Zhang $Y$, Fan $S$, Meng Q, Ma $Y$, Katiyar $P$ et al. Brca1 interaction with human papillomavirus oncoproteins. J Biol Chem 2005;280:33165-33177.

284. Filippova $\mathrm{M}$, Johnson MM, Bautista M, Filippov V, Fodor $\mathrm{N}$ et al. The large and small isoforms of human papillomavirus type 16 E6 bind to and differentially affect procaspase 8 stability and activity. J Virol 2007:81:4116-4129.

285. Veldman T, Liu X, Yuan H, Schlegel R. Human papillomavirus E6 and Myc proteins associate in vivo and bind to and cooperatively activate the telomerase reverse transcriptase promoter. Proc Natl Acad Sci U S A 2003;100:8211-8216.

286. An J, Mo D, Liu H, Veena MS, Srivatsan ES et al. Inactivation of the CYLD deubiquitinase by HPV E6 mediates hypoxia-induced NF-kappaB activation. Cancer Cell 2008;14:394-407.

287. Handa K, Yugawa T, Narisawa-Saito M, Ohno S, Fujita M et al. E6AP-dependent degradation of DLG4/PSD95 by high-risk human papillomavirus type 18 E6 protein. J Virol 2007:81:1379-1389.

288. Brimer N, Lyons C, Vande Pol SB. Association of E6AP (Ube3a) with human papillomavirus type 11 E6 protein. Virology 2007:358:303-310.

289. Favre-Bonvin A, Reynaud C, Kretz-Remy C, Jalinot P. Human papillomavirus type $18 \mathrm{E} 6$ protein binds the cellular PDZ protein TIP-2/GIPC, which is involved in transforming growth factor beta 
signaling and triggers its degradation by the proteasome. J Virol 2005;79:4229-4237.

290. Jeong KW, Kim HZ, Kim S, Kim YS, Choe J. Human papillomavirus type $16 \mathrm{E} 6$ protein interacts with cystic fibrosis transmembrane regulator-associated ligand and promotes E6-associated protein-mediated ubiquitination and proteasomal degradation. Oncogene 2007:26:487-499.

291. Degenhardt YY, Silverstein SJ, Gps SSJ. Gps2, a protein partner for human papillomavirus E6 proteins. J Virol 2001;75:151-160.

292. Vos RM, Altreuter J, White EA, Howley PM. The ubiquitin-specific peptidase USP15 regulates human papillomavirus type 16 E6 protein stability. J Virol 2009;83:8885-8892.

293. White EA, Kramer RE, Tan MJ, Hayes SD, Harper JW et al. Comprehensive analysis of host cellular interactions with human papillomavirus E6 proteins identifies new E6 binding partners and reflects viral diversity. J Virol 2012;86:13174-13186.

294. Liu X, Dakic A, Zhang Y, Dai Y, Chen R et al. Hpv E6 protein interacts physically and functionally with the cellular telomerase complex. Proc Natl Acad Sci U S A 2009;106:18780-18785.

295. Latorre IJ, Roh MH, Frese KK, Weiss RS, Margolis B et al. Viral oncoprotein-induced mislocalization of select PDZ proteins disrupts tight junctions and causes polarity defects in epithelial cells. J Cell Sci 2005;118:4283-4293.

296. Storrs $\mathrm{CH}$, Silverstein SJ. Patj, a tight junction-associated PDZ protein, is a novel degradation target of high-risk human papillomavirus E6 and the alternatively spliced isoform $18 \mathrm{~Eb}$. J Virol 2007:81:4080-4090.

297. Jha S, Vande Pol S, Banerjee NS, Dutta AB, Chow LT et al. Destabilization of Tip60 by human papillomavirus E6 results in attenuation of Tip60-dependent transcriptional regulation and apoptotic pathway. Mol Cell 2010;38:700-711.

298. Kukimoto I, Aihara S, Yoshiike K, Kanda T. Human papillomavirus oncoprotein $\mathrm{E} 6$ binds to the $\mathrm{C}$-terminal region of human minichromosome maintenance 7 protein. Biochem Biophys Res Commun 1998:249:258-262.

299. Srivenugopal KS, Ali-Osman F. The DNA repair protein, O(6)methylguanine-DNA methyltransferase is a proteolytic target for the E6 human papillomavirus oncoprotein. Oncogene 2002;21:5940-5945

300. Lee SS, Glaunsinger B, Mantovani F, Banks L, Javier RT. Multi-Pdz domain protein MUPP1 is a cellular target for both adenovirus E4-ORF1 and high-risk papillomavirus type 18 E6 oncoproteins. J Virol 2000;74:9680-9693.

301. Gewin L, Myers H, Kiyono T, Galloway DA. Identification of a novel telomerase repressor that interacts with the human papillomavirus type-16 E6/E6-AP complex. Genes Dev 2004:18:2269-2282

302. Katzenellenbogen RA, Egelkrout EM, Vliet-Gregg P, Gewin LC, Gafken PR et al. NFX1-123 and poly(A) binding proteins synergistically augment activation of telomerase in human papillomavirus type 16 E6-expressing cells. J Virol 2007;81:3786-3796.

303. Werness BA, Levine AJ, Howley PM. Association of human papillomavirus types 16 and 18 E6 proteins with $\mathrm{p} 53$. Science 1990;248:76-79.

304. Crook T, Tidy JA, Vousden KH. Degradation of p53 can be targeted by HPV E6 sequences distinct from those required for p53 binding and trans-activation. Cell 1991;67:547-556.

305. Guccione E, Lethbridge KJ, Killick N, Leppard KN, Banks L. Hpv E6 proteins interact with specific PML isoforms and allow distinctions to be made between different pod structures. Oncogene 2004:23:4662-4672.

306. Spanos WC, Hoover A, Harris GF, Wu S, Strand GL et al. The PDZ binding motif of human papillomavirus type 16 E6 induces PTPN13 loss, which allows anchorage-independent growth and synergizes with Ras for invasive growth. J Virol 2008;82:2493-2500.

307. Hoover AC, Strand GL, Nowicki PN, Anderson ME, Vermeer PD et al. ImpairedPTPN13 phosphatase activity in spontaneous or HPV-induced squamous cell carcinomas potentiates oncogene signaling through the MAP kinase pathway. Oncogene 2009;28:3960-3970.

308. Jing M, Bohl J, Brimer N, Kinter M, Vande Pol SB. Degradation of tyrosine phosphatase PTPN3 (PTPH1) by association with oncogenic human papillomavirus E6 proteins. J Virol 2007:81:2231-2239.

309. Chen JJ, Reid CE, Band V, Androphy EJ. Interaction of papillomavirus E6 oncoproteins with a putative calcium-binding protein. Science 1995;269:529-531.

310. Kranjec C, Tomaic V, Massimi P, Nicolaides L, Doorbar J et al. The high-risk HPV E6 target Scribble (hScrib) is required for HPV E6 expression in cervical tumour-derived cell lines. Papillomavirus Res 2016:2:70-77.

311. Gao Q, Srinivasan S, Boyer SN, Wazer DE, Band V. The E6 oncoproteins of high-risk papillomaviruses bind to a novel putative gap protein, E6TP1, and target it for degradation. Mol Cell Biol 1999:19:733-744.

312. Gao Q, Kumar A, Singh L, Huibregtse JM, Beaudenon $\mathrm{S}$ et al. Human papillomavirus E6-induced degradation of E6TP1 is mediated by E6AP ubiquitin ligase. Cancer Res 2002;62:3315-3321.

313. Hampson L, Li C, Oliver AW, Kitchener HC, Hampson IN. The PDZ protein TIP-1 is a gain of function target of the HPV16 E6 oncoprotein. Int J Oncol 2004:25:1249-1256.

314. Iftner T, Elbel M, Schopp B, Hiller T, Loizou JI et al. Interference of papillomavirus E6 protein with single-strand break repair by interaction with XRCC1. Embo J 2002;21:4741-4748.

315. Degenhardt YY, Silverstein S. Interaction of zyxin, a focal adhesion protein, with the E6 protein from human papillomavirus type 6 results in its nuclear translocation. J Virol 2001;75:11791-11802.

316. Rey O, Lee S, Baluda MA, Swee J, Ackerson B et al. The E7 oncoprotein of human papillomavirus type 16 interacts with F-actin in vitro and in vivo. Virology 2000;268:372-381.

317. Antinore MJ, Birrer MJ, Patel D, Nader L, McCance DJ. The human papillomavirus type 16 E7 gene product interacts with and trans-activates the AP1 family of transcription factors. Embo J 1996:15:1950-1960.

318. Pang CL, Toh SY, He P, Teissier S, Ben Khalifa Y et al. A functional interaction of E7 with B-Myb-MuvB complex promotes acute cooperative transcriptional activation of both $\mathrm{S}$ - and $\mathrm{M}$-phase genes. (129 C). Oncogene 2014;33:4039-4049.

319. Lee D, Lim C, Seo T, Kwon H, Min $\mathrm{H}$ et al. The viral oncogene human papillomavirus E7 deregulates transcriptional silencing by Brm-related gene 1 via molecular interactions. J Biol Chem 2002;277:48842-48848.

320. McIntyre MC, Ruesch MN, Laimins LA. Human papillomavirus E7 oncoproteins bind a single form of cyclin $E$ in a complex with CDK2 and p107. Virology 1996;215:73-82.

321. Yaginuma $Y$, Eguchi A, Yoshimoto M, Ogawa K. The PxDLLCxE sequence in conserved region 2 of human papilloma virus 18 protein E7 is required for E7 binding to centromere protein C. Oncology 2012;83:210-217.

322. Wang YW, Chang HS, Lin CH, Yu WCY. Hpv-18 E7 conjugates to c-myc and mediates its transcriptional activity. Int J Biochem Cell Biol 2007;39:402-412.

323. Oh K-J, Kalinina A, Wang J, Nakayama K, Nakayama KI, KJ 0 , Nakayama KI et al. The papillomavirus E7 oncoprotein is ubiquitinated by $\mathrm{UbcH7}$ and cullin 1- and Skp2-containing E3 ligase. J Virol 2004;78:5338-5346.

324. Liang YJ, Chang HS, Wang CY, Yu WCY. Dyrk1 A stabilizes HPV16E7 oncoprotein through phosphorylation of the threonine 5 and threonine 7 residues. Int J Biochem Cell Biol 2008:40:2431-2441.

325. Campo-Fernandez B, Morandell D, Santer FR, Zwerschke W Jansen-Durr P. Identification of the FHL2 transcriptional coactivator as a new functional target of the E7 oncoprotein of human papillomavirus type 16. J Virol 2007;81:1027-1032.

326. Luscher-Firzlaff JM, Westendorf JM, Zwicker J, Burkhardt $H$ Henriksson $\mathrm{M}$ et al. Interaction of the fork head domain transcription 
factor MPP2 with the human papilloma virus 16 E7 protein: enhancement of transformation and transactivation. Oncogene 1999;18:5620-5630.

327. Mileo AM, Abbruzzese C, Vico C, Bellacchio E, Matarrese P et al. The human papillomavirus-16 E7 oncoprotein exerts antiapoptotic effects via its physical interaction with the actin-binding protein gelsolin. Carcinogenesis 2013;34:2424-2433.

328. Ajiro $M$, Zheng ZM. E6^E7, a novel splice isoform protein of human papillomavirus 16, stabilizes viral E6 and E7 oncoproteins via Hsp90 and GRP78. mBio 2015;6:e02068-14.

329. Mileo AM, Abbruzzese C, Mattarocci S, Bellacchio E, Pisano P et al. Human papillomavirus-16 E7 interacts with glutathione S-transferase P1 and enhances its role in cell survival. PLoS One 2009;4:e7254.

330. Bodily JM, Mehta KP, Laimins LA. Human papillomavirus E7 enhances hypoxia-inducible factor 1-mediated transcription by inhibiting binding of histone deacetylases. Cancer Res 2011;71:1187-1195.

331. Clawson GA, Bui V, Xin P, Wang N, Pan W. Intracellular localization of the tumor suppressor HtrA1/Prss11 and its association with HPV16 E6 and E7 proteins. J Cell Biochem 2008;105:81-88.

332. Mannhardt B, Weinzimer SA, Wagner M, Fiedler M, Cohen $P$ et al. Human papillomavirus type 16 E7 oncoprotein binds and inactivates growth-inhibitory insulin-like growth factor binding protein 3. Mol Cell Biol 2000;20:6483-6495.

333. Spitkovsky D, Hehner SP, Hofmann TG, Moller A, Schmitz ML. The human papillomavirus oncoprotein E7 attenuates NF-kappa $\mathrm{B}$ activation by targeting the Ikappa B kinase complex. J Biol Chem 2002;277:25576-25582.

334. Guo Y, Zhang X, Xu Q, Gong F, Shi X et al. Human papillomavirus 16 oncoprotein E7 retards mitotic progression by blocking Mps1MAP4 signaling cascade. Oncogene 2019:38:5959-5970.

335. Morandell D, Kaiser A, Herold S, Rostek U, Lechner S et al. The human papillomavirus type 16 E7 oncoprotein targets Mycinteracting zinc-finger protein-1. Virology 2012;422:242-253.

336. Mileo AM, Piombino E, Severino A, Tritarelli A, Paggi MG et al. Multiple interference of the human papillomavirus-16 E7 oncoprotein with the functional role of the metastasis suppressor Nm23-H1 protein. J Bioenerg Biomembr 2006:38:215-225.

337. Luo X, Donnelly CR, Gong W, Heath BR, Hao Y et al. HPV16 drives cancer immune escape via NLRX1-mediated degradation of sting. J Clin Invest 2020;130:1635-1652.

338. Nguyen CL, Munger K. Human papillomavirus E7 protein deregulates mitosis via an association with nuclear mitotic apparatus protein 1. J Virol 2009:83:1700-1707.

339. Eberhard J, Onder Z, Moroianu J. Nuclear import of high risk HPV16 E7 oncoprotein is mediated by its zinc-binding domain via hydrophobic interactions with Nup62. Virology 2013;446:334-345.

340. Panayiotou T, Michael S, Zaravinos A, Demirag E, Achilleos $\mathrm{C}$ et al. Human papillomavirus E7 binds Oct4 and regulates its activity in HPV-associated cervical cancers. PLoS Pathog 2020;16:e1008468.

341. Hu T, Ferril S, Snider A, Barbosa M. In-Vivo analysis of HPV E7 protein association with pRb, p107 and p130. Int J Oncol 1995;6:167-174.
342. Todorovic B, Nichols AC, Chitilian JM, Myers MP, Shepherd TG et al. The human papillomavirus E7 proteins associate with p190RhoGAP and alter its function. J Virol 2014;88:3653-3663.

343. Berezutskaya E, Bagchi S. The human papillomavirus E7 oncoprotein functionally interacts with the $\$ 4$ subunit of the $26 \mathrm{~S}$ proteasome. J Biol Chem 1997;272:30135-30140.

344. Zwerschke W, Mazurek S, Massimi P, Banks L, Eigenbrodt E et al. Modulation of type M2 pyruvate kinase activity by the human papillomavirus type 16 E7 oncoprotein. Proc Natl Acad Sci U S A 1999:96:1291-1296.

345. Bischof O, Nacerddine K, Dejean A. Human papillomavirus oncoprotein E7 targets the promyelocytic leukemia protein and circumvents cellular senescence via the Rb and $p 53$ tumor suppressor pathways. Mol Cell Biol 2005;25:1013-1024.

346. Pim D, Massimi P, Dilworth SM, Banks L. Activation of the protein kinase B pathway by the HPV-16 E7 oncoprotein occurs through a mechanism involving interaction with PP2A. Oncogene 2005;24:7830-7838.

347. De Luca A, Mangiacasale R, Severino A, Malquori L, Baldi A et al. E1A deregulates the centrosome cycle in a Ran GTPasedependent manner. Cancer Res 2003;63:1430-1437.

348. Angeline M, Merle E, Moroianu J. The E7 oncoprotein of high-risk human papillomavirus type 16 enters the nucleus via a nonclassical Ran-dependent pathway. Virology 2003;317:13-23.

349. Severino A, Abbruzzese C, Manente L, Valderas AA, Mattarocci $S$ et al. Human papillomavirus-16 E7 interacts with Siva-1 and modulates apoptosis in $\mathrm{HaCaT}$ human immortalized keratinocytes. J Cell Physiol 2007;212:118-125.

350. Habig M, Smola H, Dole VS, Derynck R, Pfister H et al. E7 proteins from high- and low-risk human papillomaviruses bind to TGFbeta-regulated Smad proteins and inhibit their transcriptional activity. Arch Virol 2006;151:1961-1972.

351. Prathapam T, Kuhne C, Banks L. The HPV-16 E7 oncoprotein binds SKIP and suppresses its transcriptional activity. Oncogene 2001;20:7677-7685.

352. Mazzarelli JM, Atkins GB, Geisberg JV, Ricciardi RP. The viral oncoproteins Ad5 E1A, HPV16 E7 and SV40 tag bind a common region of the TBP-associated factor-110. Oncogene 1995;11:1859-1864.

353. Vambutas A, DeVoti J, Pinn W, Steinberg BM, Bonagura VR. Interaction of human papillomavirus type 11 E7 protein with TAP-1 results in the reduction of ATP-dependent peptide transport. Clin Immunol 2001:101:94-99.

354. Massimi P, Pim D, Storey A, Banks L. HPV-16 E7 and adenovirus E1A complex formation with TATA box binding protein is enhanced by casein kinase II phosphorylation. Oncogene 1996;12:2325-2330.

355. Jeon JH, Choi KH, Cho SY, Kim CW, Shin DM et al. Transglutaminase 2 inhibits Rb binding of human papillomavirus E7 by incorporating polyamine. Embo J 2003;22:5273-5282.

356. Zwerschke W, Mannhardt B, Massimi P, Nauenburg S, Pim D et al. Allosteric activation of acid alpha-glucosidase by the human papillomavirus E7 protein. J Biol Chem 2000;275:9534-9541.

\section{Five reasons to publish your next article with a Microbiology Society journal}

1. The Microbiology Society is a not-for-profit organization.

2. We offer fast and rigorous peer review - average time to first decision is 4-6 weeks.

3. Our journals have a global readership with subscriptions held in research institutions around the world.

4. $80 \%$ of our authors rate our submission process as 'excellent' or 'very good'.

5. Your article will be published on an interactive journal platform with advanced metrics.

Find out more and submit your article at microbiologyresearch.org. 